\title{
FORMATION OF PHOTORECEPTORS IN LARVAL AND ADULT GOLDFISH $^{1}$
}

\author{
PAMELA RAYMOND JOHNS ${ }^{2}$ \\ Department of Neurobiology, Harvard Medical School, Boston, Massachusetts 02115 \\ Received June 1, 1981; Revised September 8, 1981; Accepted October 9, 1981
}

\begin{abstract}
Histogenesis of the photoreceptor layer in the retina of goldfish was studied morphometrically and with thymidine radioautography at the light microscopic level. At hatching, the photoreceptor layer is poorly differentiated. The cells in the outer nuclear layer that are postmitotic at hatching differentiate into cones. Two to 3 days after hatching, rod nuclei appear in the outer nuclear layer, and rods begin to differentiate. Rods and rod nuclei accumulate across the retina during larval and juvenile life. It is proposed that rods are generated in the outer nuclear layer by dividing progenitor cells that may be analogous to subventricular cells. Rod progenitors appear to derive from clusters of undifferentiated cells in the inner nuclear layer, which are called neurogenic clusters. Some of these cells apparently migrate across the outer plexiform layer from the inner to the outer nuclear layer and then divide to produce rods. The ontogenetic sequence of photoreceptor development in the larval retina is recapitulated continuously in the circunferential growth zone at the margin of the juvenile and adult retina. New rods continue to be inserted, but at a slower rate, throughout the adult retina; this may explain how the density of rods is maintained constant despite the expansion of the retinal surface that accompanies growth of the eye.
\end{abstract}

In most vertebrates, neurogenesis in the retina is completed during embryonic or early postembryonic stages. In teleost fish, however, production of new retinal neurons persists beyond embryonic and larval stages into adult life (Müller, 1952; Wagner, 1974; Johns and Easter, 1977; Johns, 1977). This prolonged period of neurogenesis is associated with an enormous amount of growth: in some fish, the surface area of the retina can increase 100fold in just a few years (Lyall, 1957a). Part of this increase in retinal size is accounted for by expansion of pre-existing tissue, and the remainder is due to the addition of new cells. Recent experiments using $\left[{ }^{3} \mathrm{H}\right]$ thymidine to label dividing cells and their progeny have shown that a mitotically active germinal zone encircles the retinal margin (ora terminalis) in juvenile and adult fish (Scholes, 1976; Johns, 1977, 1981; Meyer, 1978). New cells generated there are added to the perimeter of the retina in concentric annuli. A similar mode of circumferential cell addition has been described in the growing retinas of larval amphibians (Gaze and Watson, 1968; Straznicky

\footnotetext{
' This work was supported by United States Public Health Service Grant EY03301. The technical assistance of Ms. Yu-Wen Hwang, Mr. Marc Pelloquin, Mr. Andrew Ting, and Mr. James Voyvodic is most gratefully acknowledged. Dr. S. S. Easter provided insightful comments on the manuscript.

${ }^{2}$ Present address: Department of Anatomy and Cell Biology, The University of Michigan Medical School, Ann Arbor, MI 48109.
}

and Gaze, 1971; Jacobson, 1976; Beach and Jacobson, 1979).

Until recently, it was thought that all new neurons are added appositionally at the retinal margin. It is now apparent that this is not strictly correct. There have been a number of reports which together hint that the genesis of one particular class of retinal neuron, the rods, does not follow this orderly concentric pattern. For example, several histological studies have suggested that cones are the only photoreceptors in the retinas of larvae of several species of teleost fish, though adults of these species have both rods and cones (Ali, 1959, 1961; Blaxter, 1968, 1975; Blaxter and Jones, 1967; Blaxter and Staines, 1970; Wagner, 1974; T. Banachek and G. Streisinger, personal communication). Rods first appear during larval development in these fish, and rod nuclei gradually accumulate in the outer nuclear layer as the eye grows (Lyall, 1957a, b; Wagner, 1974). Various hypotheses have been proposed to account for the addition of rods to retinal regions far removed from the source of proliferating cells at the retinal margin. These include recruitment of cells from other retinal layers and transformation of other retinal cells into rods (Blaxter and Jones, 1967; Lyall, 1957 a, b). Sandy and Blaxter (1980) have reported very recently that rods are produced by mitotically active cells in the outer nuclear layer within differentiated (laminated) regions of the larval teleost retina.

In juvenile and adult fish, the retina grows not only by 
cell addition but also by expansion (Lyall, 1957a; Ali, 1963, 1964; Johns, 1977, 1981; Johns and Easter, 1977). Here again, the rods follow a unique developmental path. Whereas the density of cones, ganglion cells, and other neurons decreases as the retina enlarges, the density of rods is maintained approximately constant (Müller, 1952; Wagner, 1974; Johns and Easter, 1977). The explanation for this is unclear. Results from $\left.{ }^{3} \mathrm{H}\right]$ thymidine radioautography have some bearing on this issue. Following an injection of $\left[{ }^{3} \mathrm{H}\right]$ thymidine, many labeled nuclei are found in the circumferential growth zone, but in some preparations, a few labeled nuclei have been observed within the retina (Scholes, 1976; Johns, 1977; Meyer, 1978; C. Stürmer, personal communication). They are found most frequently in the outer nuclear layer, especially at longer survival times, and are presumed to be rods. The scattered labeled rod nuclei extend centripetally from the growth annulus toward the central retina. It is reasonable to suspect that the differential pattern of labeling in the outer nuclear layer might be involved with maintaining the constant density of rods during growth in juvenile and adult fish, though only one of these earlier studies addressed this issue (Johns, 1977). The results from that study seemed to support Müller's (1952) proposal that new neurons are all born at the margin but that new rods are subsequently displaced laterally, toward the center of the retina, by mechanical shearing forces generated by the expanding retinal tissue. The present radioautographic studies cast doubt on this interpretation, however.

This study was undertaken with two goals in mind: to reconcile the discrepancies in the interpretations of previous radioautographical studies concerning the origin of rods in juvenile and adult goldfish and to apply the technique of $\left[{ }^{3} \mathrm{H}\right]$ thymidine labeling to larval retinas to determine the birth dates of the original rods. The results can be summarized simply: in both larval and adult fish, new cells, believed to be rods, are formed throughout the retina by mitotic division of scattered precursor cells. These dividing cells are not confined to a discrete germinal zone but are interspersed among differentiated neurons. Their progeny appear to differentiate only into rods. Preliminary reports of portions of this work have appeared elsewhere (Johns, 1980; Johns and Hwang, 1981; Johns and Fernald, 1981).

\section{Materials and Methods}

Embryonic and larval fish. Goldfish embryos of the "Comet" strain were obtained from Carolina Biological Supply (Burlington, NC). When they were received, on May 8, 1980, most were at stage 23 of embryonic development, equivalent to $60 \mathrm{hr}$ postfertilization at $21^{\circ} \mathrm{C}$ (Kajishima, 1960). Development was allowed to proceed at room temperature $\left(20\right.$ to $\left.24^{\circ} \mathrm{C}\right)$ in the pond water in which they were shipped. Hatching occurred at stage 25 , which corresponds to $100 \mathrm{hr}$ postfertilization at $21^{\circ} \mathrm{C}$ (Kajishima, 1960).

Fish were injected at selected postembryonic stages as described under "Results." They were first anesthetized in $0.001 \%$ tricaine methanesulfonate (Sigma, St. Louis, $\mathrm{MO})$ and then injected with 0.5 to $1.25 \mu \mathrm{Ci}$ of $\left[{ }^{3} \mathrm{H}\right]$ thymidine. The tip of the micropipette used for the injection was broken to a diameter of about $30 \mu \mathrm{m}$, and it was positioned just dorsal to the developing air bladder. After injection, the fish were transferred through two changes of sterile water and allowed to recover overnight in sterile Holtfreter's solution (Rugh, 1962) before they were returned to pond water. The length of the survival period following injection ranged from $17 \mathrm{hr}$ to 252 days. The young fry began feeding at about 4 days after hatching. They were offered pulverized commercial fish food (Purina Trout Chow) supplemented with live nauplii of brine shrimp (Artemia spp.).

Juvenile and adult fish. Goldfish "Comets," 3 to 13 $\mathrm{cm}$ standard length, were purchased from Ozark Fisheries (Richland, MO) or from Grassy Forks Fisheries (Martinsville, IN). Some small fish ( 3 to $5 \mathrm{~cm}$ standard length) were bought at a local pet store. They were kept in aerated, artificial pond water (Allee et al., 1940) at room temperature under combined natural and laboratory fluorescent illumination. The animals were fed daily with commercially prepared fish food (TetraFin or Wardley's Goldfish Food and Purina Trout Chow), and freshly chopped earthworms were given at least once a week. Fish were maintained in the laboratory for at least 2 months before they were used for radioautographic experiments.

Experimental fish were weighed and injected intraperitoneally with $\left[{ }^{3} \mathrm{H}\right]$ thymidine $(95$ to $104 \mathrm{Ci} / \mathrm{mmol})$. Twenty to $30 \mu \mathrm{Ci} / \mathrm{gm}$ of body weight was injected in a single dose or in a series of up to six injections at 8- or 12-hr intervals. Survival periods ranged from $1 \mathrm{hr}$ to 180 days. Specific details are given where appropriate under "Results."

Histological and radioautographical techniques. Young larvae were fixed whole by immersion in 2.5\% glutaraldehyde and 1 to $2 \%$ paraformaldehyde in $0.065 \mathrm{~m}$ phosphate buffer overnight at $4^{\circ} \mathrm{C}$. Older larvae were decapitated or enucleated, and the heads or eyes were fixed in mixed buffered aldehydes with the addition of $0.1 \%$ picric acid. The eyes of adult fish were enucleated before fixation. The cornea was opened, the lens was removed, and its diameter was measured with a caliper. The posterior chamber of the eye was gently flushed with fixative to remove most of the vitreous and to aid penetration of the fixative. The eyecups were immersed overnight in fixative at $4^{\circ} \mathrm{C}$. The following day, the eyecup was bisected along either the dorsoventral or the nasotemporal meridian using two, new single-edged razor blades moved against one another in a scissor-like stroke. This method of slicing the globe resulted in minimal distortion of the retinal surface.

Tissues were dehydrated in graded ethanols to $95 \%$, infiltrated overnight, and embedded in methacrylate (JB4, Polysciences or Sorvall Embedding Medium, DuPont). Serial sections, cut at $3 \mu \mathrm{m}$ on 0.5 -inch-wide glass knives using a JB-4 microtome (Sorvall-DuPont), were mounted on acid-cleaned slides and dried on a hot plate at about $80^{\circ} \mathrm{C}$. The plane of sectioning was parallel to either the dorsoventral or nasotemporal meridian; half-eyes were sectioned parallel to the previously cut surface.

For radioautography, slides with mounted methacrylate sections were rinsed in distilled water and dipped in Kodak NTB-2 emulsion warmed to $40^{\circ} \mathrm{C}$ and diluted 1:1 with distilled water. The slides were allowed to dry standing vertically in a closed chamber and then were 
stored with desiccant for 2 to 4 weeks at $4^{\circ} \mathrm{C}$. The emulsion was developed in Kodak D-19 for 2 min at $18^{\circ} \mathrm{C}$, fixed, and rinsed. Sections were post-stained with methylene blue $10.065 \%$ in $5 \%$ methanol in phosphate buffer, $\mathrm{pH}$ 6.9) or with Lee's combination of methylene blue and basic fuchsin (Polysciences Data Sheet 123). Differentiation of the stain, if required, was accomplished with $1 \%$ glacial acetic acid; alcohols were avoided as they softened the methacrylate. The slides then were air-dried thoroughly, cleared in xylene, and coverslipped with Permount.

In some preparations, the melanin in the pigmented retinal epithelium was bleached before the sections were stained. Bleaching greatly improved the visibility of the photoreceptor processes, especially the rods, which, in the normal light-adapted retina, are obscured by the dark pigment granules. Methacrylate sections were treated for 1 to $5 \mathrm{~min}$ in $1 \%$ potassium permanganate, followed by $1 \%$ oxalic acid for an equivalent length of time. When bleaching was required for radioautographs, it was done prior to application of the emulsion.

Morphometric techniques. For each larval eye, the section that passed through the center of the lens was traced with a Leitz drawing tube at a magnification of $\times 140$ to 370 . The following dimensions were measured on the drawings: the lens diameter, the retinal length (defined as the linear distance along the retina from one margin to the other at midlevel in the retina), and the angle subtended by the retina (measured with respect to the center of the lens). The surface area of the retina $(S)$ was calculated, assuming the retina to be a portion of a sphere:

$$
S=\int_{0}^{\theta / 2} 2 \pi r^{2} \sin \theta d \theta
$$

where $\theta$ is the angle in degrees subtended by the retina and $r$ is the radius of the sphere from which the retina is derived. The value of $r$ was calculated from the measured retinal length $(l)$ using the proportionality:

$$
\begin{gathered}
\frac{2 \pi r}{l}=\frac{360}{\theta} \\
\text { so } r=57.3 \frac{l}{\theta}
\end{gathered}
$$

The values of $S$ calculated for the right and left eyes of a single fish varied by no more than $10 \%$.

Sections from older, larger eyes were traced similarly at a magnification of $\times 68$. Since these eyes were bisected and then sectioned parallel to the cut surface, the first sections from the block were meridional; that is, they passed through or very near the center of the eye. The retinal length was measured in one of these sections and $r$ was calculated as above. The retinal surface area was calculated using a value of $\theta=185^{\circ}$ determined in a previous study of the ocular geometry in adult goldfish (Easter et al., 1977).

The positions of $\left[{ }^{3} \mathrm{H}\right]$ thymidine-labeled nuclei were marked on tracings of some of the radioautographs. A nucleus was considered labeled if there were more than five silver grains in the emulsion overlying it. Details of which sections were drawn will be taken up under "Results." The intent was to demonstrate the distribu- tion of labeling across the retina at various times after injection. Regions of retina with labeled nuclei were reconstructed with the aid of a Megatek 7000 computer graphics system linked to a PDP 11/34 computer.

To determine the numbers and the density of retinal cells, selected regions of retinas from larval and adult fish were traced using a $\times 100$ oil immersion objective. Each sample covered a segment of retina 85 to $130 \mu \mathrm{m}$ long. Nuclei of identified cells were outlined and linear densities (number of cells per mm of retinal length) were determined. To calculate planimetric densities (number per $\mathrm{mm}^{2}$ of retinal surface area), the counts were corrected for split nuclei with Konigsmark's (1970) modification of Abercrombie's factor. Nuclear diameters were measured in thick sections $(8 \mu \mathrm{m})$; only those nuclei which were contained entirely within the section were measured (Mori and Christensen, 1980).

\section{Results}

When goldfish embryos hatch, they are about $5 \mathrm{~mm}$ in length and have a prominent yolk sac. Swimming movements are sporadic, jerky, and uncoordinated until the 2nd or 3rd day when the air bladder inflates. During the next few weeks, the larval fish gradually assume all of the characteristics of mature goldfish. Kajishima (1960) recognized three stages of larval development in goldfish: hatching is at stage 25 , the air bladder is seen at stage 26 , and during stage 27 , the fin rays begin to form. Maturation is completed at stage 28 , about 3 weeks posthatch. The changes in external morphology that take place during the larval period are gradual and the transitions between stages are subtle.

Cytological development of the larval retina. Differentiation of the retina is also a slow and gradual process that is not completed until late in postembryonic development. Figure 1 is a photomicrograph of a horizontal section through the eye of a newly hatched goldfish. The neural retina is laninated, but the cytoarchitectural proportions are vastly different from those in the adult retina. Figure 2 compares, at the same magnification, the retina of an adult goldfish. The most striking difference between the larval and the adult retina is in the relative thickness of the photoreceptor layer. In the adult, this layer accounts for approximately half of the entire thickness of the retina, whereas in the young larval retina, it is nearly absent. Not only are the photoreceptors poorly differentiated at hatching but there are very few cells in the outer nuclear layer. On Figures 1 and 2, the outer nuclear layer is indicated by brackets for ease of comparison. Notice that the outer nuclear layer of the adult retina contains one discrete row of large, oval, pale cone nuclei and three to four rows of smaller, spindle-shaped, darker rod nuclei. In the larval retina, in contrast, there is only a single uniform row of tall columnar nuclei in the outer nuclear layer. The thickness and number of rows of nuclei in the outer nuclear layer increase during larval growth, suggesting that it must acquire cells during this period. In marked contrast to the outer nuclear layer, the other two nuclear layers have an abundance of cells in newly hatched larvae. Both the inner nuclear and ganglion cell layers are, in fact, thicker in the larval retina than they are in the adult. There are seven or more rows 

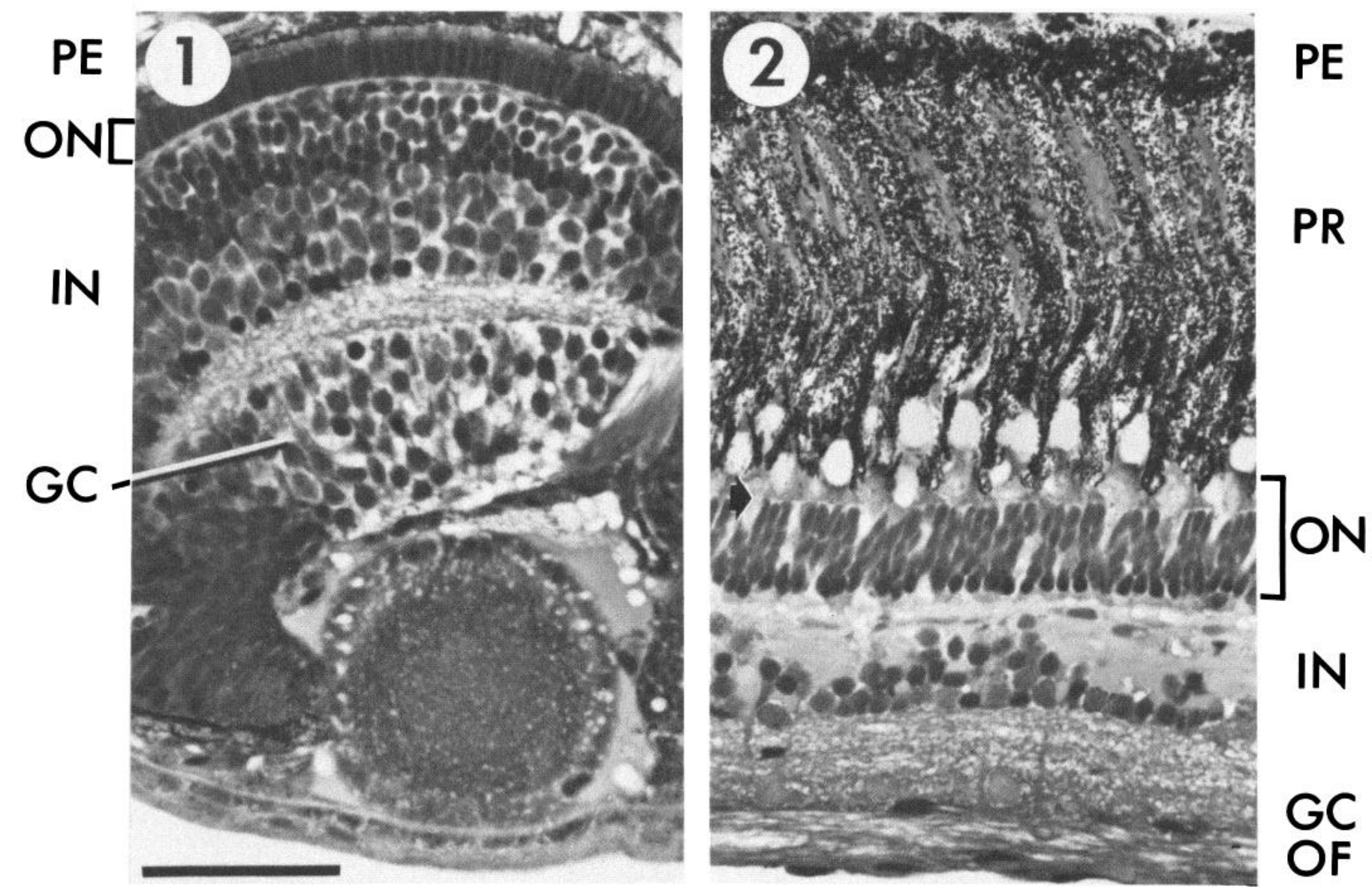

Figure 1. The eye of a newly hatched goldfish larva. The layers of the retina are labeled, from sclerad to vitread, as follows: pigmented retinal epithelium $(P E)$, outer nuclear layer $(O N$ and enclosed by brackets), inner nuclear layer $(I N)$, and ganglion cell layer $(G C)$. The rounded lens and cornea are at the bottom, and part of the optic nerve can be seen penetrating through the retina on the right. The calibration bar is $50 \mu \mathrm{m}$.

Figure 2. The retina of an adult goldfish. The layers are labeled as in Figure 1; photoreceptor layer, $P R$; optic fiber layer, $O F$. The sclerad row of large, pale nuclei in the outer nuclear layer are cones; they are at the level of the external limiting membrane $($ arrow). There are four rows of smaller, darker rod nuclei vitread to the row of cone nuclei. The outer plexiform layer is the cellfree zone between the outer nuclear layer and the inner nuclear layer. The internal limiting membrane is at the bottom. The magnification is the same as in Figure 1.

of ganglion cells at hatching and only a single, interrupted row in the adult; similarly, the inner nuclear layer decreases from about nine to less than five rows.

Not only does the cytoarchitecture change dramatically during postembryonic growth but the surface area of the retina increases by more than two orders of magnitude from hatching to 4 years of age. In newly hatched fish, the retinal area is about $0.05 \mathrm{~mm}^{2}$ (Fig. 3). During the first 2 months, the retina grows rapidly to about 1.0 $\mathrm{mm}^{2}$. Growth continues at a slower rate in juvenile and adult fish. The retina and lens grow conformally; therefore, the correlation between lens diameter and retinal area is high $\left(\right.$ retinal area $=7.67(\text { lens diameter })^{2}+0.0025$; coefficient of correlation, $r=0.98$ ).

There are two sources of error in the above calculation of retinal area which should be mentioned. In larvae 10 days of age or older, the eye usually collapsed during histological processing; therefore, $\theta$, the angle subtended by the retina, was often difficult to determine precisely. In the better preparations, the eye appeared to closely approximate a hemisphere, and therefore, a value of $\theta=$ $180^{\circ}$ was used to calculate retinal area in older larvae and young juvenile fish. The eyes from very young larvae were not distorted as often, probably because the lens, which nearly filled the intraocular space, helped to maintain the shape of the globe. In these eyes, the angle subtended by the retina was clearly less than $180^{\circ}$. A more accurate determination of ocular geometry and retinal area requires further studies, however. It also was noted, but not examined systematically, that, in younger larvae, the eyeball is elongated in the nasotemporal (horizontal) plane; a slight asymmetry in the same axis persists in eyes of adult goldfish (Stell and Hárosi, 1976).

The transformation and maturation of the larval retina into the adult form occurs over the first several months of postembryonic life. Figures 4 through 9 illustrate the sequence of retinal differentiation in the goldfish. These micrographs are all from the most mature, central region of each retina, since at all ages, peripheral regions were less developed, in accord with the well known centrifugal gradient of retinal maturation described in many other vertebrate species, including goldfish (Sharma and Ungar, 1980).

Figure 4 is a photomicrograph of the retina of a newly 


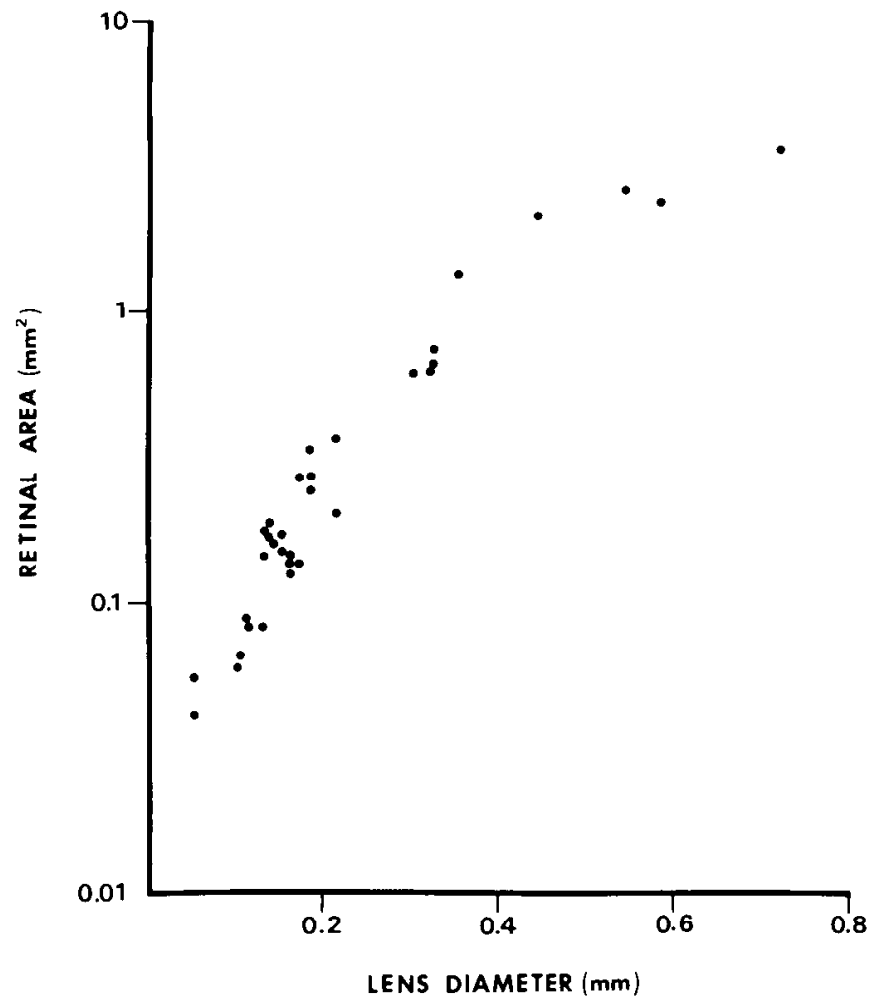

Figure 3. The retinal area of larval and juvenile goldfish. The retinal area in square millimeters, calculated as described in the text, is plotted as a function of the diameter of the lens in millimeters. Note that the ordinate has a logarithmic scale. Each point represents one retina. The age of the fish ranged from newly hatched to 252 days old.

hatched goldfish. Note again the single row of nuclei in the outer nuclear layer. All of these nuclei have the same form: they are straight and columnar with fine granular chromatin and an occasional nucleolus. They abut against the apical surface of the neuroepithelium but do not protrude beyond it. The only evidence of the differentiation of photoreceptors is the appearance of small, immature inner segments, rounded nubbins which project into the extraretinal space between neural retina and pigmented retinal epithelium.

At 2 to 3 days posthatch (stage 26), the nuclei in the outer nuclear layer assume a more irregular, hourglass shape (Fig. 5). They are constricted at the level of the external limiting membrane through which they now protrude. The processes of the photoreceptor cells are more evident at this stage; round inner segments are capped by incipient outer segments. All of the differentiating photoreceptors appear to be cones as judged by the size, shape, staining characteristics, and position of their nuclei and the morphology of the developing inner and outer segments. In addition to the young cone nuclei, a new type of cell appears in the outer nuclear layer at this stage. These are small, irregular or rounded, dark nuclei which lie along the vitread border of the outer nuclear layer as indicated by the small arrows in Figure 5 . Since this is the position later occupied by rod nuclei and since developing rod outer segments are seen just after these nuclei appear, it is likely that they are rods, though a more definitive identification requires electron microscopy.
At 10 days, differentiation of photoreceptors has progressed further and the outer segments have elongated. Both cones and rods now can be distinguished more easily, especially in bleached preparations (Fig. 6). The outer segments of the young rods lie more sclerad (in the light-adapted eye) and are thicker than those of the cones, and their inner segments are small. In unbleached sections, the pigment-filled fingers of pigmented retinal epithelium cells are draped around the young photoreceptors (Fig. 7).

The outer nuclear layer is not fully mature even after 6 weeks. Presumed rod nuclei still comprise but a single row in the outer nuclear layer (Fig. 8). The cones are much larger, and the rod outer segments are more abundant (Fig. 9). Rods continue to accumulate slowly over the next several months.

Changes in the density of retinal cells with growth. The above description of the larval retina suggests that the content of cells in the outer nuclear layer increases during larval development. This is demonstrated quantitatively in Figure 10, which is a graph of linear densities of retinal nuclei (numbers per mm of retinal length). The single row of columnar nuclei in the outer nuclear layer were counted as cones and all other nuclei in that layer were considered to be rods. This identification of rods was admittedly somewhat arbitrary, particularly for the younger stages, since many of these nuclei did not have all of the cytological characteristics of rods. It is not unreasonable to suspect that these cells were rods in various stages of maturation, but further documentation at the electron microscopic level is certainly required before a definitive identification is possible. The counts thus represent an upper limit to the number of rods at each age. All cells in the inner nuclear layer were included in the counts for that layer. Cells in the ganglion cell layer were not counted, since, at early stages, it was impossible to distinguish between neurons and non-neuronal cells. Some of the cells in or near the ganglion cell layer were undoubtedly glia and others were certainly immature vascular elements associated with the developing blood vessels on the vitreal surface.

Figure 10 shows a progressive increase in the linear density of rod and presumptive rod nuclei from 0 to over $1,150 / \mathrm{mm}$ from hatching through adulthood. The density of rod nuclei peaked in fish about 2 years old with lens diameters of 2 to $3 \mathrm{~mm}$ (corresponding to a standard body length of about $8 \mathrm{~cm}$ ). With further increase in size of the eye, the linear density of rods seemed to decrease slightly. The largest fish were $13 \mathrm{~cm}$ in standard body length and up to 5 years old. In striking contrast to the rods, the linear density of both cone nuclei and cells in the inner nuclear layer decreased with growth. A decrease in cell density is typical of the postembryonic growth of the retina in most vertebrates (Johns, 1981); it is associated with expansion of the retinal surface. The density of cone nuclei thus decreased from 350 to $100 / \mathrm{mm}$. The density of cells in the inner nuclear layer dropped precipitously from 1,500 to $300 / \mathrm{mm}$; a transient dip occurred at a lens diameter of 0.1 to $0.15 \mathrm{~mm}$, but this may be artifactual. Indeed, the standard error (not shown) of the point in question overlaps with those of adjacent points so that no statistical significance can be attributed to this slight discrepancy in cellular density. The rest of the 
curve is so smooth, however, that it is hard to ignore this anomalous point, particularly since it coincides with the appearance of the first presumptive rods at about 3 days posthatch. Other evidence, to be discussed below, suggests that both the dip and the excessive decline in overall density of cells may, in fact, represent a real loss of cells from this layer.

The linear densities shown in Figure 10 were derived from primary data not corrected for split nuclei. Thus, conclusions about absolute cell numbers or proportions of various types of cells cannot be drawn from this graph. However, when the nuclear counts are corrected and the ratio of rods to cones is calculated, it can be seen that larger retinas have relatively more rods (Fig. 11). The ratio of rods to cones increases from 0 at hatching to $1: 1$ in larvae about 1 to 2 months old ( $0.5 \mathrm{~mm}$ lens diameter), to $6: 1$ at about 1 year of age $(1.7 \mathrm{~mm}$ lens diameter $)$, and finally to $15: 1$ in 4 - or 5-year-old fish $(4 \mathrm{~mm}$ lens diameter).

The conclusion is simple: rods increase in density, while the density of other retinal cells decreases. This alteration in the proportions of retinal cells begins in young larvae and continues into adult life. The increase in the density of rod nuclei implies that new rods are added to the outer nuclear layer within differentiated regions. There is no indication from these counts that cones are added similarly. The origin of these extra rods is investigated in the next section.

Cytogenesis in the larval retina: Patterns of labeling with $\left[{ }^{3} H\right]$ thymidine. To determine the place and time of origin of rods, postembryonic goldfish of various ages were injected with $\left[{ }^{3} \mathrm{H}\right]$ thymidine. Six larval fish were given a single injection on the 1st or the 2 nd postembryonic day, and they were sacrificed 1 to 9 days later. The pattern of labeling of retinal nuclei at 4 days is illustrated in Figure 12A. All nuclei in the circumferential germinal zone were labeled, but the heaviest label was over the newest retinal nuclei in the laminated region immediately adjacent to the germinal cells. The label indicates that these cells were generated by mitotic divisions during the preceding 4 days. Similar labeled nuclei were found around the entire retinal circumference. Labeled photoreceptor and horizontal cell nuclei sometimes extended up to about $25 \mu \mathrm{m}$ centralward from the otherwise sharp edge of the labeled annulus (Fig. 12B). Very rare labeled nuclei were seen elsewhere in the inner nuclear layer and sometimes in the outer plexiform layer (Fig. 12C). Results were similar with shorter survival times.

By 9 days after injection, the pattern of labeling had changed somewhat. In the peripheral retina, the annulus of labeled neurons was further from the margin and the germinal cells were only lightly labeled. This is consistent with the sequential addition of new cells at the margin as described in the introduction. A few heavily labeled horizontal cell and cone nuclei were inside of the sharp centralmost edge of the labeled annulus as in the retinas at 1 to 4 days survival. There were, in addition, more labeled nuclei within the retinal area enclosed by the labeled annulus. In fact, labeled nuclei were found in both the outer and inner nuclear layers, whereas at 1 day, there had been only a few in the inner nuclear layer. A similar pattern of labeling was found in another fish injected at 5 days posthatch and allowed to survive until
11 days of age. In the outer nuclear layer, only the rounded nuclei in the vitread row were labeled (Fig. 13); none of the tall columnar nuclei of the young cones were labeled except those adjacent to the ora terminalis. Labeled nuclei were found at various levels in the inner nuclear layer (Fig. 13), and some even extended beyond it into or across the outer plexiform layer. They tended to be elongated and often were grouped in clusters. A similar cluster of elongated cells in the inner nuclear layer of an uninjected 10-day-old larval goldfish is illustrated in Figure 14. These cells are very reminiscent of ventricular cells, or neuroepithelial germinal cells (Boulder Committee, 1970), from which the surrounding retinal neurons were derived in the embryonic retina. Therefore, they will tentatively be called "neurogenic clusters."

Another group of five larval goldfish was injected with $\left[{ }^{3} \mathrm{H}\right]$ thymidine at 12 or 19 days of age and sacrificed 1 to 30 days later. The pattern of labeling in the circumferential germinal zone was similar to that in the younger larvac. In the inner nuclear layer at 1 day, there were elongated labeled nuclei and pairs of nuclei (Fig. 15). Unlike in the earlier stages, however, in these older larvae, label was seen in the outer nuclear layer over nuclei in the vitread row at 1 day following injection (Fig. 16). The implication is that both the inner nuclear layer and the outer nuclear layer contain proliferating cells in the 1- to 3-week-old larvae, whereas only the inner nuclear layer has such cells in newly hatched fish.

An increase in the survival time following injection at 12 or 19 days of age did not change the pattern of labeling except that there were more labeled nuclei in the outer nuclear layer (Fig. 17) and a higher proportion of them were lightly labeled. Both observations are consistent with repeated cycles of cell division of the labeled progenitors. Again, labeled nuclei were only in the vitread row of rod nuclei in the outer nuclear layer, and no label was found over cone nuclei.

Injections of $\left[{ }^{3} \mathrm{H}\right]$ thymidine in young juvenile goldfish, 1 to 2 months of age, produced radioautographs essentially similar to those from late larval fish. Cells in the circumferential germinal zone continued to divide and to produce annuli of new retina. Scattered labeled nuclei were seen in the outer nuclear layer and the inner nuclear layer as before, but in these older retinas, a higher proportion of the dividing cells were in the outer nuclear layer compared with the inner nuclear layer (see below). Labeled rod nuclei persisted for up to 252 days, the longest survival time examined.

Laminar distribution of labeled nuclei. The above description included several statements about the relative numbers of labeled nuclei in various retinal layers. These parameters now are examined more rigorously.

Figure 18 illustrates the apportionment of labeled nuclei between the outer nuclear layer and the inner nuclear layer as a function of the age of the fish at the time of injection. The length of the postinjection survival period is indicated by the symbols: open circles, 1 day or less; solid circles, over 1 day. Labeled nuclei in the more vitread layers and in the annular growth zone were not included in these counts. First, I will discuss the experiments at short survival times, indicated by the open circles. The nuclei labeled in these retinas are those of proliferating or recently postmitotic cells. In larvae less 




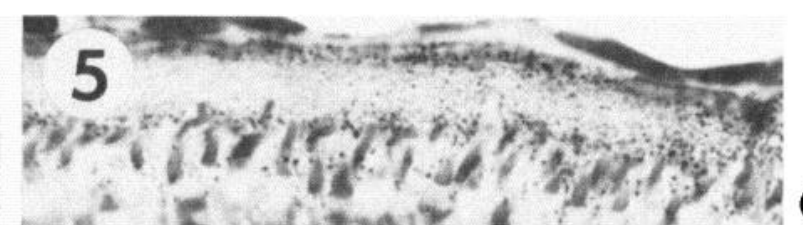
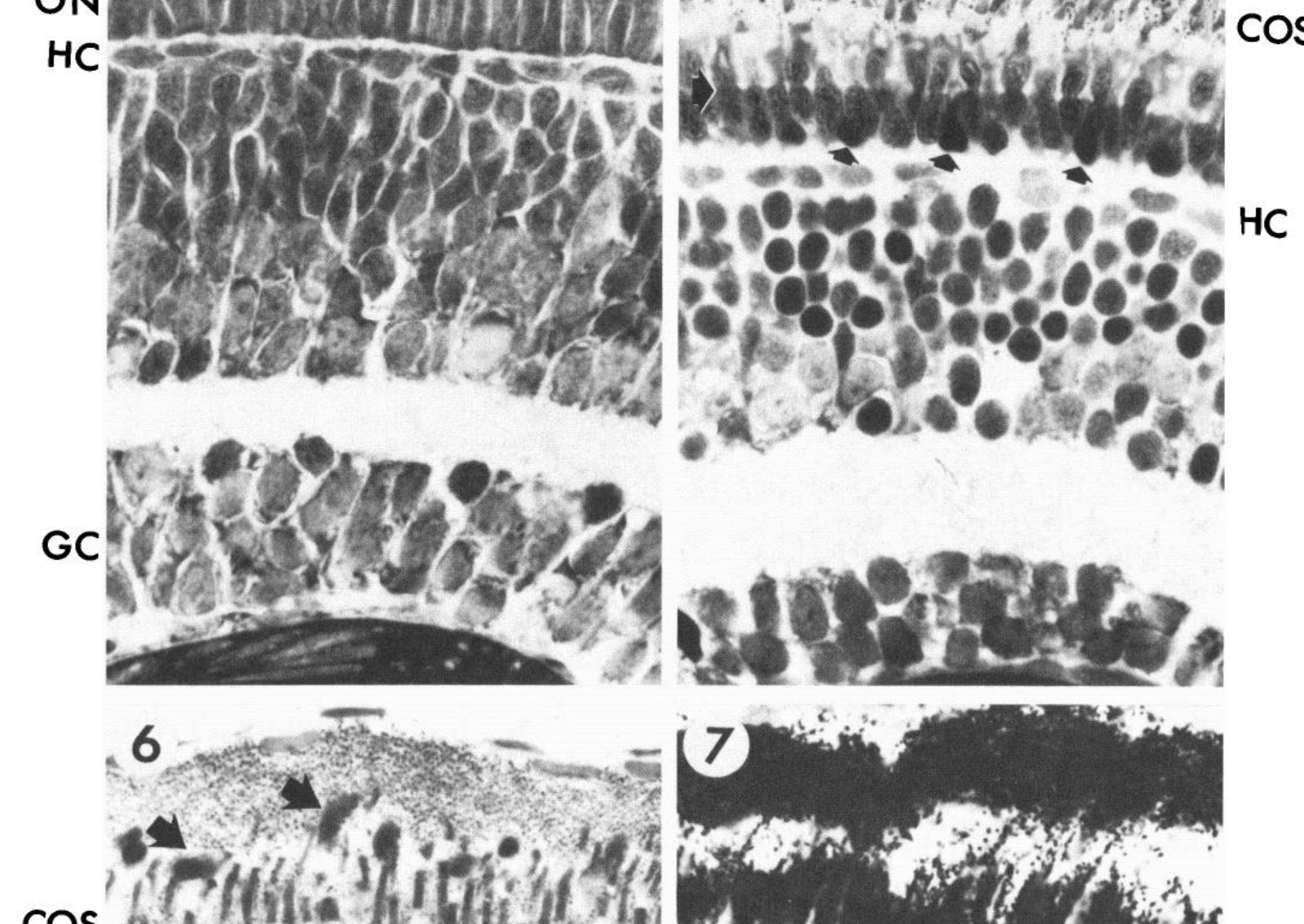




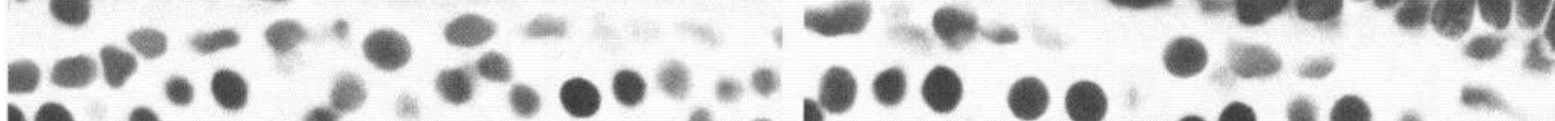
10 40.8:80

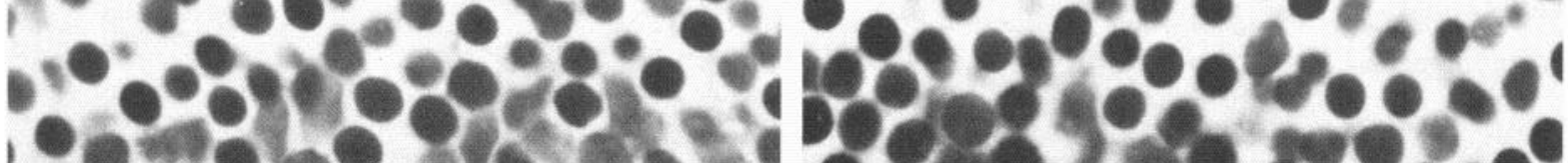
i.

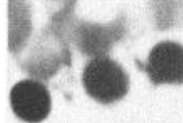

Figure 4 to 7. 


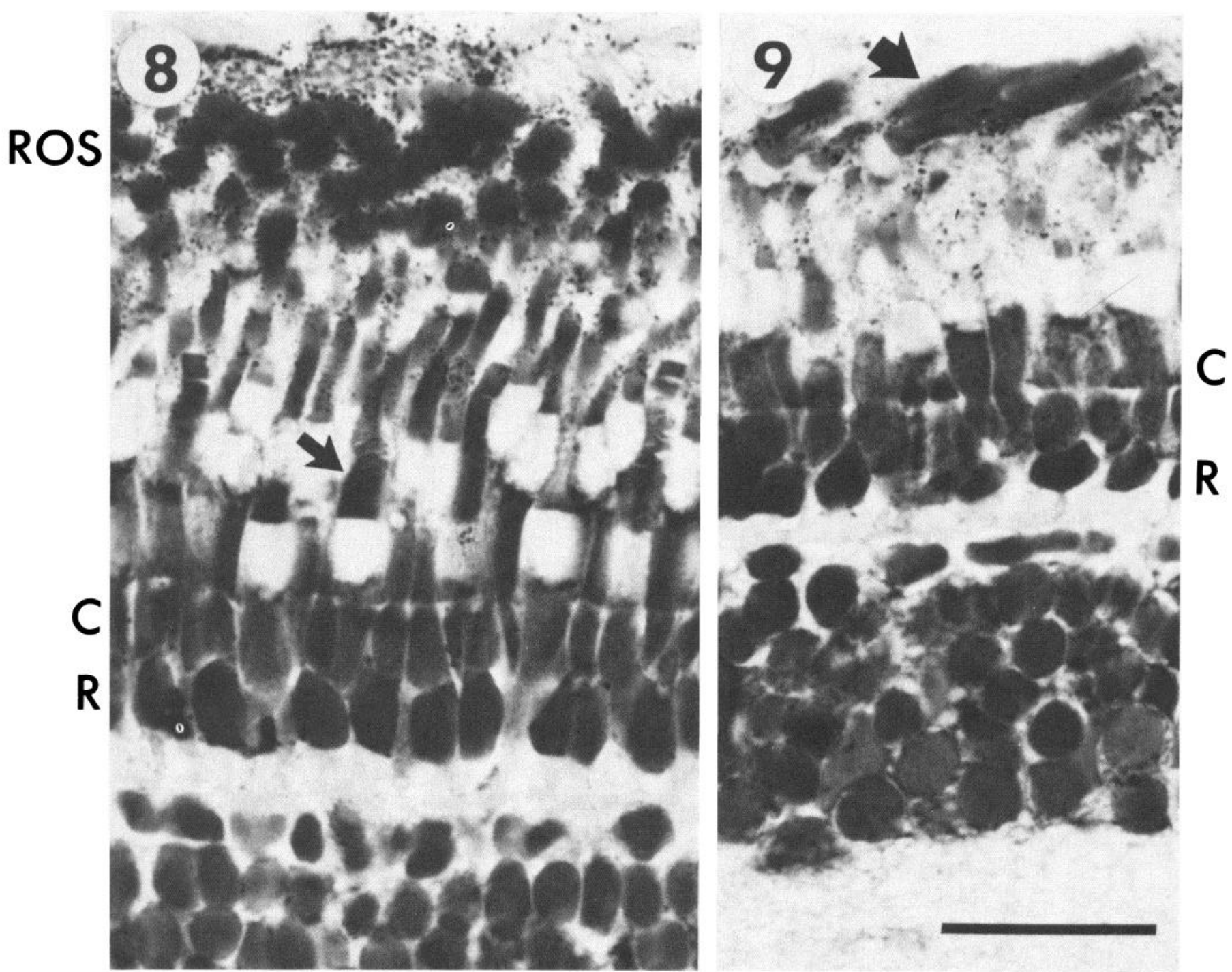

Figures 4 to 9 . Histogenesis of the larval retina.

Figure 4. The retina of a 1-day-old larval goldfish. The arrow points to the apical surface (presumptive external limiting membrane), and the outer nuclear layer $(O N)$ is the single row of columnar nuclei just below. The outer plexiform layer is barely discernible beneath it. Nuclei of horizontal cells $(H C)$ have just begun to separate from the other cells in the inner nuclear layer. The ganglion cell layer $(G C)$ and a part of the lens are at the bottom. The melanin was bleached in this section (see "Materials and Methods").

Figure 5. The retina of a 2-day-old larval goldfish. The nuclei of cones have an hourglass shape, constricted at the level of the external limiting membrane (arrow at the left edge of the figure). The photoreceptor processes of the cones (COS) have begun to develop. A few dark nuclei (small arrows) have appeared in the outer nuclear layer vitread to the original row of nuclei. The horizontal cell nuclei $(H C)$ are further separated from the other retinal nuclei. This section was bleached.

Figure 6. The retina of a 10-day-old larval goldfish. The cones are larger and their outer segments $(C O S)$ are longer. A few rod outer segments (large arrows) are seen in the photoreceptor layer sclerad to the cones. The outer nuclear layer contains a complete row of cone nuclei at the level of the external limiting membrane (arrow at the right edge) and vitread row of sparse rod nuclei. This section was bleached. The calibration bar is $20 \mu \mathrm{m}$ and also applies to Figures 4,5 , and 7 .

Figure 7. The retina of a 10-day-old larval goldfish. This section is from the same retina as the one in Figure 6, but the melanin has not been bleached. The arrow at the left is at the level of the external limiting membrane.

Figure 8. The retina of a 42-day-old young juvenile goldfish. The cone outer segments (arrow) have elongated and their inner segments are larger and wider. This section was cut slightly tangential to the axis of the photoreceptors so that the cones appear in multiple stacks, and the rod outer segments $(R O S)$ are cut transversely. The outer nuclear layer now has two complete rows of nuclei, one of cones $(C)$ and the other rods $(R)$. This section was bleached.

Figure 9. The retina of a 42-day-old young juvenile goldfish. In this section from the same retina as in Figure 8 , the rods $($ arrow) are cut longitudinally. They have long outer segments and small, round inner segments. Nuclei of cones $(C)$ and of rods $(R)$ are shown. The calibration bar is $20 \mu \mathrm{m}$ and also applies to Figure 8 . 


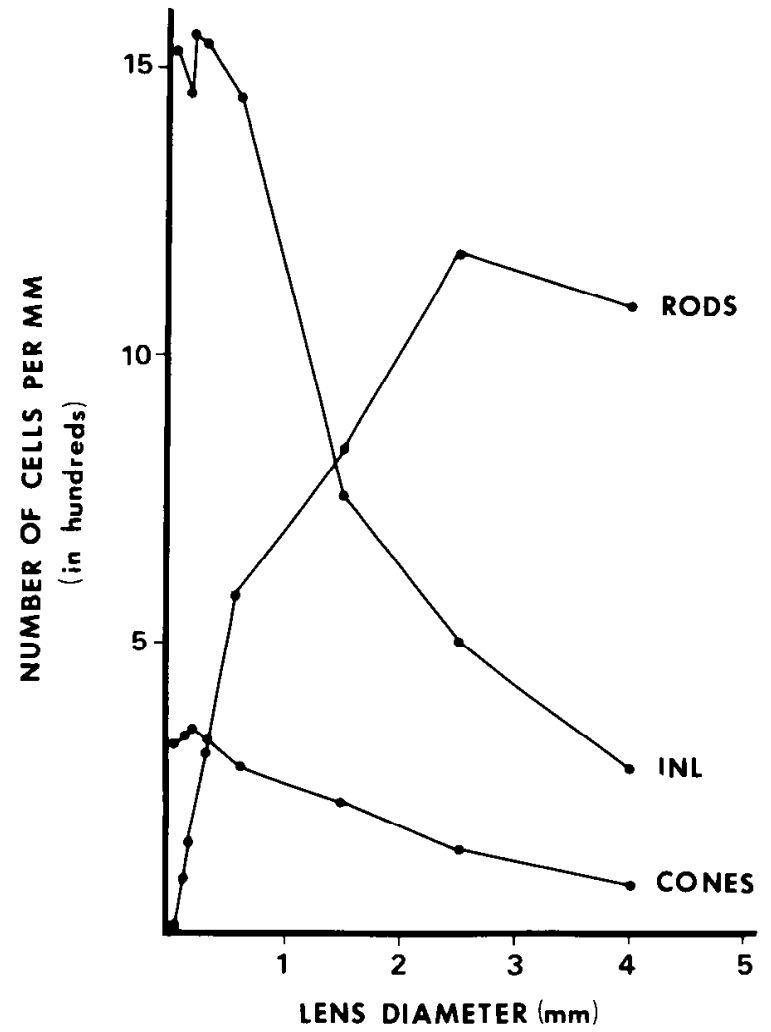

Figure 10. The linear density of cells in the retina of postembryonic goldfish. The number of cells per $\mathrm{mm}$ of retinal length is plotted as a function of the diameter of the lens in millimeters. In eyes from small fish, one sample was taken from the center of the retina in each of three meridional sections; in larger eyes, four to six samples equally spaced across the retina were counted in one meridional section. The data plotted are means of counts from two to five eyes in each of eight successive, non-overlapping ranges of lens diameter from less than 0.1 to $4.0 \mathrm{~mm}$. The fish ranged in age from newly hatched larvae to 4 or 5-year-old adults. $I N L$, cells in the inner nuclear layer.

than 1 week old, labeled nuclei were found in the inner but not in the outer nuclear layer. In older larvae, labeled nuclei of dividing cells were found in both layers: in 2- to 3 -week-old larvae, about $35 \%$ of the labeled dividing cells were in the outer nuclear layer, and in juvenile fish, the outer nuclear layer contained nearly $90 \%$ of the labeled nuclei.

Counts from retinas at longer survival periods are indicated by the solid circles in Figure 18, and the number to the right of each point is the length of the survival period in days following injection. Nuclei labeled in these preparations are the progeny of the dividing cells labeled earlier. The fraction of labeled rod nuclei in the outer nuclear layer increased with longer survival times no matter what the age of the fish at injection. Thus, in larvae injected at 1 week of age, $35 \%$ of the labeled nuclei were in the outer nuclear layer after 6 days and about $50 \%$ were there after 9 days. Likewise, for fish injected at 2 to 3 weeks of age, $70 \%$ were in the outer nuclear layer after 8 days and $85 \%$ were there after about 1 month. In juvenile fish ( 1 month or older), the fraction of labeled nuclei in the outer nuclear layer varied between 83 and $96 \%$ after 1 to 40 days, and by 180 days, almost all of the label was over rod nuclei, and few or no labeled nuclei remained in the inner nuclear layer.

The fraction of the rod population labeled by a single injection of $\left[{ }^{3} \mathrm{H}\right]$ thymidine in larval and young juvenile fish up to 50 days old averaged $1.5 \%$ (range, 0.2 to $4.7 \%$ ). In the older juveniles, on average, $0.5 \%$ (range, 0.1 to $1.8 \%$ ) of the rod nuclei in the part of the retina enclosed by the labeled annulus were labeled by the series of six injections. These figures, and those in the previous paragraph, are overestimates, since no correction was made for split labeled nuclei, portions of which would be included in radioautographs of two adjacent sections. The sections were thin enough that all nuclei which had incorporated the precursor would appear labeled in these preparations; i.e., "false negatives" were not a problem; Caviness and Barkley (1971) showed empirically that the effective path length of $\beta$ particles from tritium is about $2.5 \mu \mathrm{m}$ in methacrylate sections of neural tissue.

The data in Figure 18 are presented in terms of ratios rather than absolute numbers of labeled cells because the level of labeling was extremely variable from one eye to the next. That these figures nevertheless reflect a real shift in the apportionment of labeled nuclei between retinal layers is supported by results from two fish in which the eyes were removed at different survival times: the right eye was removed $24 \mathrm{hr}$ following injection, and the left eye was removed when the animal was killed after 30 or 110 days, respectively. Counts from the two retinas from the same fish are connected by vertical line segments in Figure 18. In both fish, there was a higher proportion of labeled nuclei in the outer nuclear layer of the second (left) eye. The total number of labeled nuclei in the outer nuclear layer of these retinas was calculated from the density of labeled nuclei and the area of the retina enclosed by the labeled annulus. In one fish, there

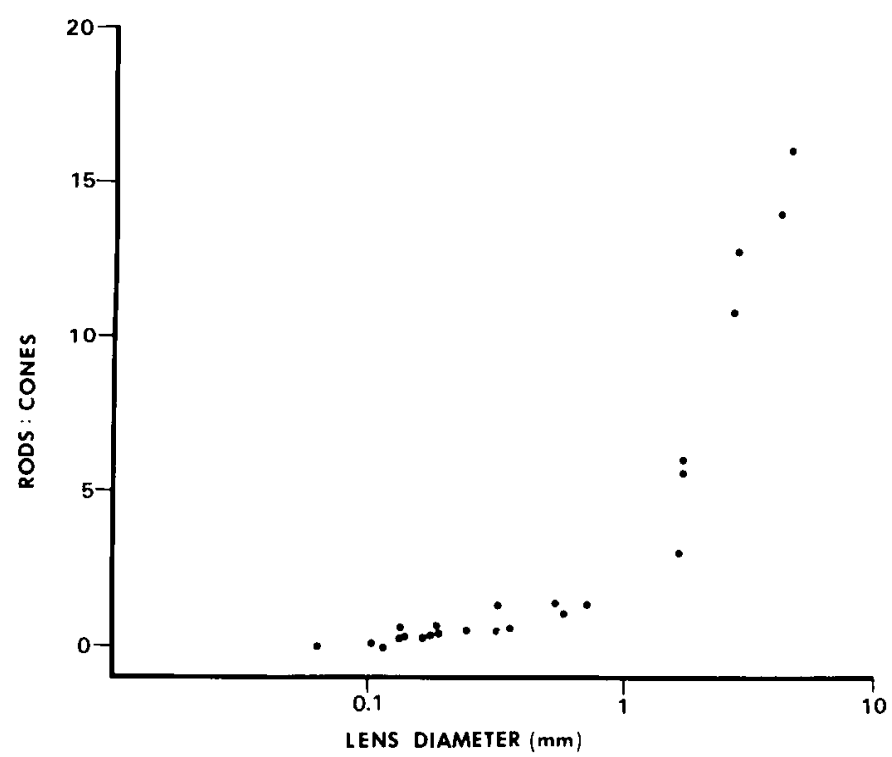

Figure 11. The ratio of rods to cones in the retina of postembryonic goldfish. The number of rods per cone, based on density of their nuclei and corrected with an Abercrombie factor, is plotted as a function of lens diameter in millimeters. Note that the abscissa has a logarithmic scale. Each point represents one retina. The fish ranged in age from newly hatched to adult. 

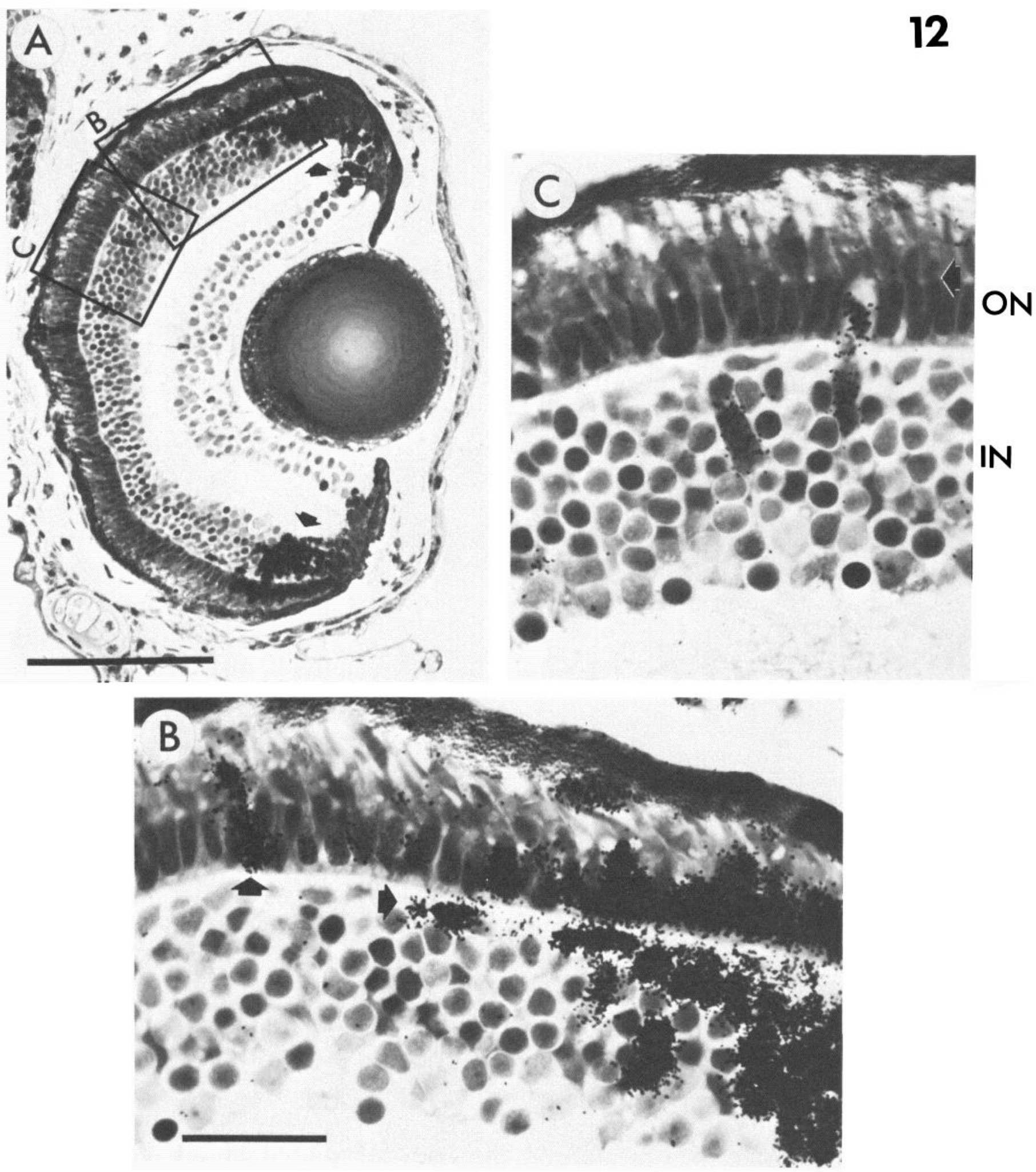

Figure 12. Radioautograph of an early larval goldfish retina. This fish was injected with $\left[{ }^{3} \mathrm{H}\right]$ thymidine at hatching and sacrificed 4 days later. $A$, A frontal section through the eye. Note the labeled cells at each retinal margin (arrows). The calibration bar is $100 \mu \mathrm{m}$. B, The central edge of the labeled annular growth zone. The arrows point to labeled horizontal cell and photoreceptor nuclei. The latter is probably a cone becarse of its hourglass shape. The calibration bar is $20 \mu \mathrm{m}$ and also applies to $C$. $C$, Labeled nuclei in the inner nuclear layer $(I N)$ and crossing the outer plexiform layer into the outer nuclear layer $(O N)$. The arrow is at the level of the external limiting membrane. 

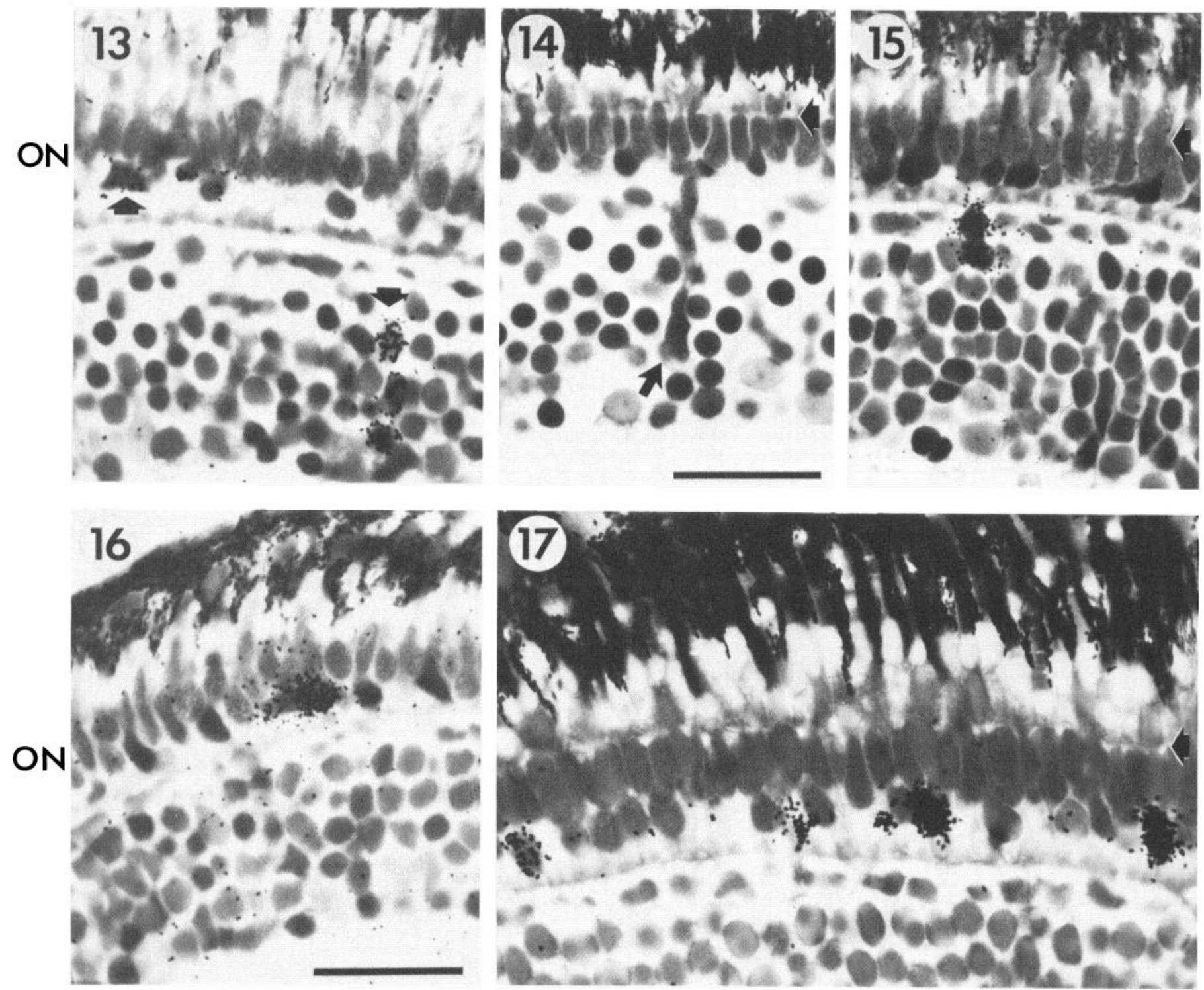

Figure 13. Radioautograph of a mid-larval retina. This fish was injected with $\left[{ }^{3} \mathrm{H}\right]$ thymidine at 2 days of age and sacrificed 9 days later. The arrows point to a string of labeled nuclei in the inner nuclear layer and to one labeled nucleus in the vitread row of the outer nuclear layer $(O N)$.

Figure 14. A cluster of cells in the inner nuclear layer. This is a section from the retina of a 10-day-old larval goldfish. A cluster of three elongated cells (arrow near the bottom) extends from the inner nuclear layer through the outer plexiform layer into the outer nuclear layer. The arrow on the right is at the level of the external limiting membrane. The calibration bar is $20 \mu \mathrm{m}$ and also applies to Figure 13.

Figures 15 and 16. Dividing cells in the late larval retina. These two radioautographs are from the retina of a 20-day-old fish injected with $\left[{ }^{3} \mathrm{H}\right]$ thymidine the previous day.

Figure 15. A pair of labeled nuclei straddling the outer plexiform layer. The arrow on the right is at the level of the external limiting membrane.

Figure 16. A labeled nucleus in the vitread row of the outer nuclear layer. The calibration bar is $20 \mu \mathrm{m}$ and also applies to Figures 15 and 17.

Figure 17. Labeled rod nuclei in the larval retina. This radioautograph is from a fish injected with [ $\left.{ }^{3} \mathrm{H}\right]$ thymidine at 19 days and sacrificed at 42 days of age. Rod nuclei in the vitread row of the outer nuclear layer are labeled; two are weakly labeled and two are heavily labeled. There are no labeled cone nuclei. The arrow is at the level of the external limiting membrane.

were 1,130 labeled nuclei in the outer nuclear layer of the right eye and 6,800 in the left; in the inner nuclear layer, there were 132 and 216 labeled nuclei, respectively. In the other fish (the one with a longer total survival time), these numbers were 4,850 and 28,900 in the outer nuclear layer and 693 and 2,490 in the inner nuclear layer of the right and left eyes, respectively. Though the total number of labeled nuclei increased in both the outer nuclear layer and the inner nuclear layer, the relative increase was greater in the outer nuclear layer. This result is consistent with a movement of some of the labeled progeny from the inner nuclear layer to the outer nuclear layer. Other explanations could account for this observation, however. The lower rate of accumulation of labeled nuclei in the 


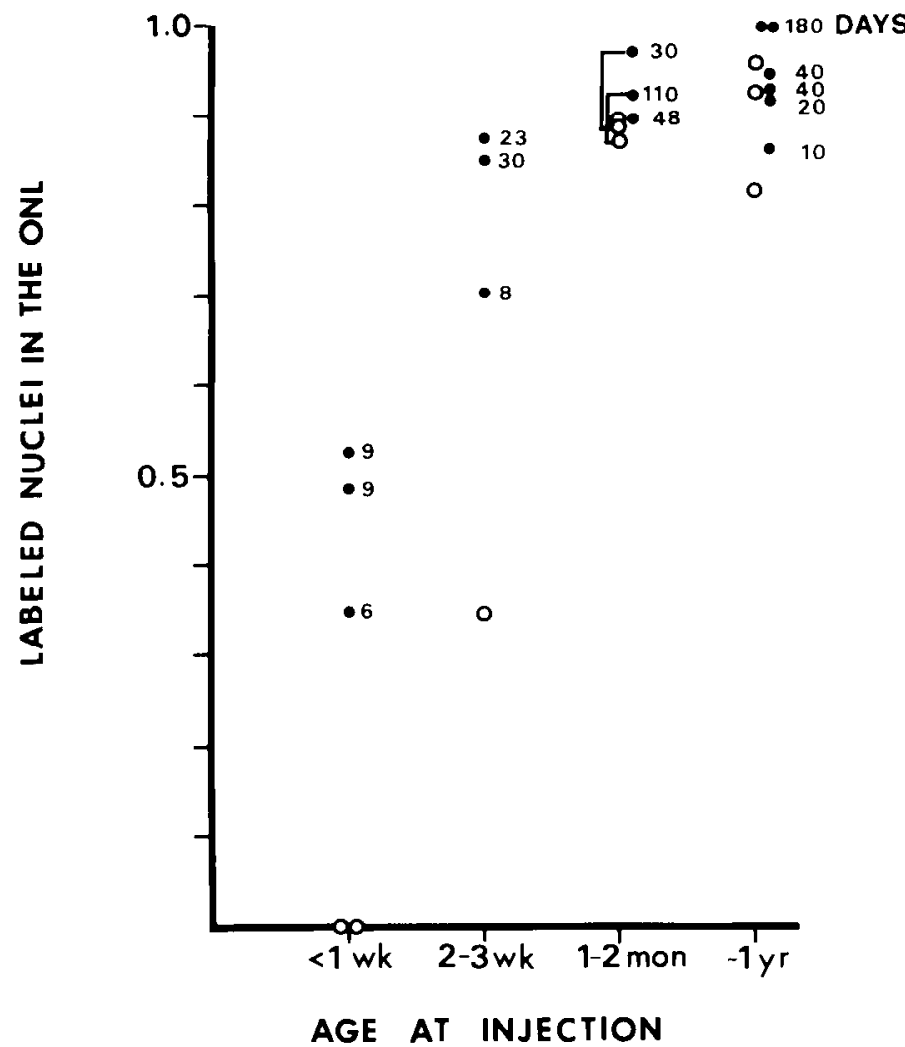

Figure 18. The fraction of labeled nuclei in the outer nuclear layer of larval and juvenile goldfish. Labeled nuclei in the inner and the outer nuclear layers were counted across the extent of the retinal region enclosed by the labeled annulus of cells produced by the circumferential germinal zone. This region represents, in all eyes, the part of the retina that was exposed to the $\left[{ }^{3} \mathrm{H}\right]$ thymidine; the retina outside of the annulus of label was added in the interval following injection. The few heavily labeled retinal nuclei (horizontal cells and cones) which were immediately adjacent to, but not quite within, the labeled annulus in the youngest retinas (see Fig. 12B) were excluded. Labeled nuclei in the vitread retinal layers (the ganglion cell and optic fiber layers), which were present in all retinas, also were not counted. In larval fish, all sections which passed through the lens, in a set of serial sections through the head, were scanned for labeled nuclei. In the larger eyes of juvenile fish ( 1 to 2 months old), nuclei were counted in sections at 15 $\mu \mathrm{m}$ intervals through the entire extent of the lens. In eyes from 1-year-old fish, seven parameridional sections within an $80-\mu \mathrm{m}$ interval were counted. The fraction of labeled nuclei in the outer nuclear layer $(O N L)$ is plotted as a function of the age of the fish at injection. Each point represents one retina. The open circles are from eyes which were removed 1 day after injection. The solid circles are from eyes removed at longer intervals; the length of the survival period in days is given by the number to the right of each point. In two of the fish injected at 1 to 2 months of age, the right eye was removed at 1 day and the left eye was removed several days later. Counts from the two eyes from the same fish are connected by vertical line segments.

inner nuclear layer might result from a slower rate of mitotic division, fewer progeny leaving the mitotic cycle to differentiate, or some of the new cells dying. None of these possibilities is ruled out by the present experiments.

Addition of rods in the juvenile retina. Figure 18 has demonstrated that the addition of nuclei to the outer nuclear layer of the goldfish retina continues beyond larval stages into juvenile life. The radioautographical evidence for this is now presented.

Multiple injections of $\left[{ }^{3} \mathrm{H}\right]$ thymidine were administered over a 2- to 3-day interval in six juvenile goldfish, three that were purchased from a local pet store and three that were raised in the laboratory. The latter were 7 months old, and all fish were the same size $(3$ to $5 \mathrm{~cm}$ standard length). In all eyes, labeled nuclei were found in the circumferential germinal zone and also scattered across the retina. A substantial majority of the scattered labeled nuclei were in the outer nuclear layer (Fig. 19). Many, especially those in peripheral regions of the retina, were along the vitread border of the outer nuclear layer. Label also was found over elongated nuclei and pairs of nuclei which straddled the outer plexiform layer (Fig. 20 ), and elongated or rounded nuclei were seen in the inner nuclear layer. Pairs of labeled nuclei often were seen in the outer nuclear layer for a few days following the injection. With longer survival times, fewer labeled pairs were seen; this implies either that the two daughter cells moved apart after dividing or, more likely, that only one daughter differentiated, while the other continued to proliferate. The labeled nuclei in the outer nuclear layer after longer survival times differentiated into rods as Figure 21 demonstrates. Labeled rod nuclei were found at all levels in the vitread rows of the outer nuclear layer. As in the larval retinas, no labeled cone nuclei were seen except in the annular growth zone.

It is appropriate at this point to mention the labeled nuclei which were seen in the most vitread layers and which, up to now, have been omitted from the discussion. In retinas from juvenile fish, labeled nuclei in or near the ganglion cell and optic fiber layers were easily recognized as endothelial cells or glia (Fig. 22). In the retinas from larval fish, these layers also contained a few labeled nuclei, but glial and vascular elements often were poorly differentiated and therefore not as easy to identify with certainty. In no case, however, was label ever found over the nucleus of an identified ganglion cell in either larval or adult retinas except in the annular growth zone.

In Figure 23, the number of labeled nuclei in the outer nuclear layer is plotted as a function of survival time following a single injection. Counts from the two retinas from the same fish again are connected by line segments. From these data, a crude estimate of about $20 \mathrm{hr}$ was calculated for the doubling time of the rod progenitor population in juvenile goldfish. This graph also demonstrates the extreme variability in the level of thymidine labeling among fish: the number of labeled nuclei per section ranged from 3 to 42 . Whether this variability was due to inconsistencies in the amount of precursor administered or whether it reflected real differences among animals in either the size of the population of rod progenitors or their mitotic rate cannot be deduced from the results of this experiment.

Another group of juvenile goldfish was given multiple injections of $\left[{ }^{3} \mathrm{H}\right]$ thymidine over a 48 -hr period in an attempt to label the rod progenitor population maximally. These fish survived for 3 to 180 days from the initial injection. Again, the number of labeled nuclei in the outer nuclear layer varied greatly (from 5 to 65/ section) somewhat independent of the length of survival following injection. These fish were injected six times so 

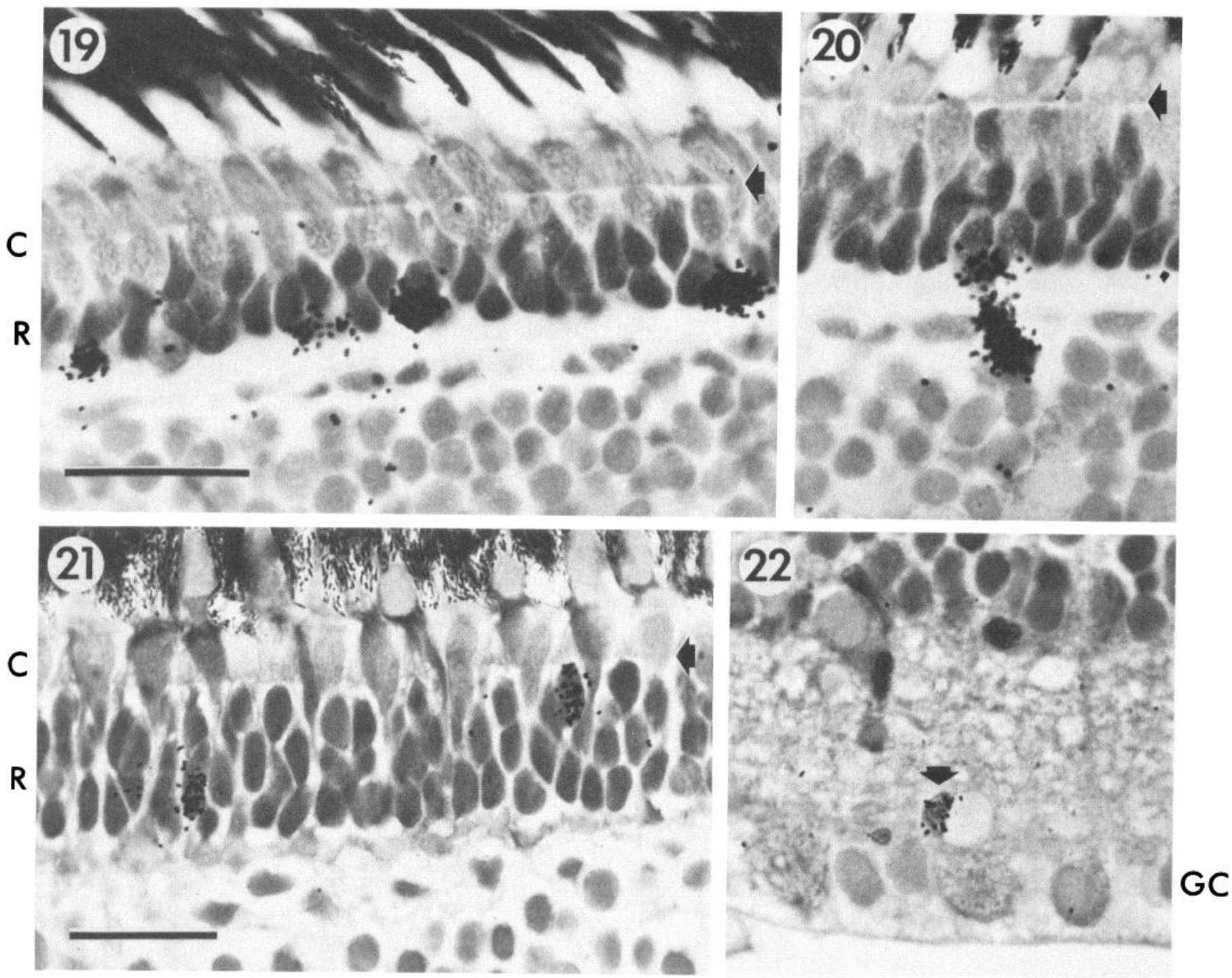

Figures 19 and 20. Dividing cells in the retina of a juvenile goldfish.

Figure 19. Labeled nuclei at the vitread border of the outer nuclear layer $4 \mathrm{hr}$ after a pulse injection of [ $\left.{ }^{3} \mathrm{H}\right]$ thymidine. Labeled nuclei are in the vitread row among nuclei of rods $(R)$; the row of cone nuclei $(C)$ contains no label. The arrow is at the level of the external limiting membrane. The calibration bar is $20 \mu \mathrm{m}$ and also applies to Figure 20.

Figure 20. A pair of labeled nuclei in the outer plexiform layer of the same retina. The arrow indicates the external limiting membrane.

Figure 21. Labeled rod nuclei in the retina of a juvenile goldfish. This radioautograph is from the retina of a fish given multiple injections of $\left[{ }^{3} \mathrm{H}\right]$ thymidine 19 to 21 days previously. The label is over rod nuclei $(R)$. Cone nuclei $(C)$ are at the level of the external limiting membrane (arrow) and are not labeled. The calibration bar is $20 \mu \mathrm{m}$ and also applies to Figure 22.

Figure 22. A labeled glial cell. This labeled glial cell (arrow) is in the ganglion cell layer $(G C)$ of the retina of a fish injected with $\left[{ }^{3} \mathrm{H}\right]$ thymidine 20 days previously.

that variations in total dosage should have been minimal. That such extreme variability in the numbers of labeled nuclei persisted nevertheless supports the suggestion that there were real individual differences in the level of mitotic activity in these retinas.

The distribution of labeled nuclei was not homogeneous across the extent of the outer nuclear layer in juvenile fish. In most sections, the majority of labeled nuclei in the outer nuclear layer were within a few hundred micrometers of the ora terminalis. Figure 24 is a set of camera lucida drawings of three meridional sections from the retina of a goldfish injected 21 days previously. Notice the string of labeled nuclei in the outer nuclear layer (solid circles) adjacent to the ora terminalis at each edge. Labeled nuclei in other layers (open circles) were more dispersed and more homogeneously distributed except near the optic disc, where the numbers of labeled glial cells increased as the optic fibers gathered to exit the eye.

In order to analyze the distribution of label more systematically, camera lucida drawings of up to seven meridional sections from each of 17 eyes were prepared, and computer graphics manipulations were used to convert information about numbers and positions of labeled nuclei in the outer nuclear layer into matrices of dots. This standardization procedure compensated for histological distortions and allowed retinas from fish of different sizes to be readily compared. Representative results 


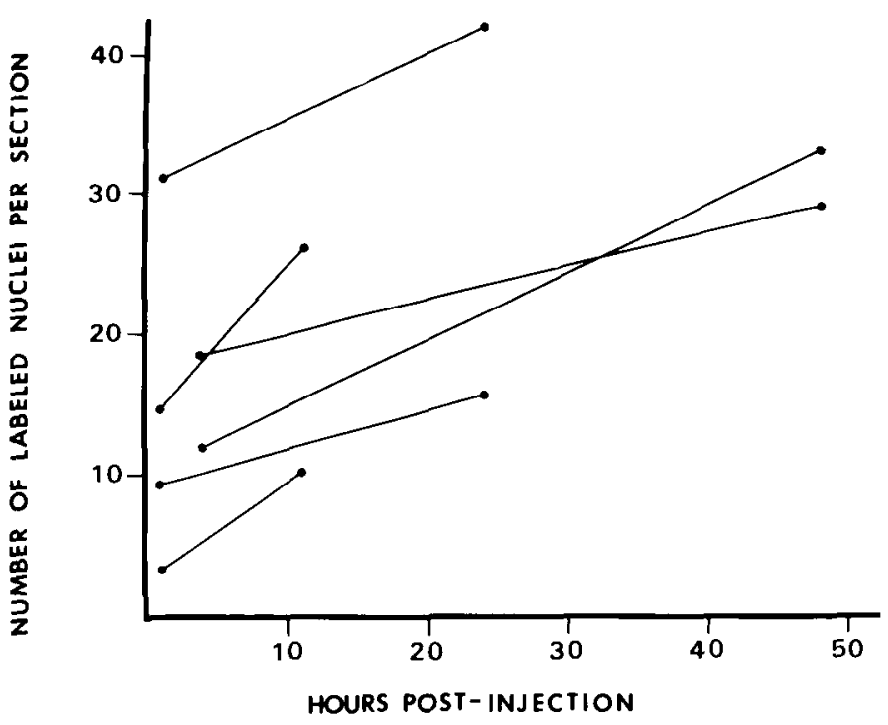

Figure 23. Increase in numbers of labeled nuclei with increased survival times. The number of labeled nuclei per section is plotted as a function of hours following injection of $\left[{ }^{3} \mathrm{H}\right]$ thymidine. Each point is the mean of 7 to 11 sections from one retina. Counts from the two retinas from a single fish are connected by line segments.

from 8 of the 17 retinas are illustrated in Figures 25 and 26. The clustering of labeled nuclei next to the ora terminalis is evident in all retinas. Other labeled nuclei are scattered throughout more central retinal regions, but these, too, are often loosely grouped together (e.g., retina 20 in Fig. 26). Some retinas had few labeled nuclei in central regions (e.g., 24 in Fig. 25), while others had many (e.g., 48 in Fig. 25). The numbers and distributions of labeled nuclei showed no systematic changes with time un to 180 days (180 in Fig. 26). The lengths of the retinal sections from this eye were adjusted so that the segment enclosed by the labeled annulus (represented by the vertical dashed lines) was equivalent to the entire retina of fish with shorter survival times. This was done so that equivalent regions of retina could be compared, since the retina outside of the annulus was added after the injection. Notice that the distribution of labeled rod nuclei is not different in the 180-day retina. From this, one can conclude that new rods produced by the rod progenitors probably differentiate in situ, perhaps at the precise retinal locus where they were born. This is an important inference because, in a previous study of retinal cell production in adult goldfish (Johns, 1977), I suggested that new rods were born in the circumferential germinal zone and were later displaced centripetally as the retina grew. The present results offer no evidence for a systematic lateral displacement of rods.

The part of the retina which contained the most labeled rods or rod progenitors was the youngest region, the outermost annulus of cells most recently formed by the circumferential germinal zone. The reason that more rods were added there became apparent on examination of the cytoarchitecture of the peripheral retina. The retina adjacent to the ora terminalis in juvenile and adult fish appeared similar to the retina of a newly hatched larval fish, and the temporal sequence of differentiation described for the larval stages (Figs. 4 to 9) was laid out spatially from the ora terminalis inward toward the center of the retina. The camera lucida drawing in Figure 27 shows that, at the extreme margin, the outer nuclear layer is a single row of columnar, undifferentiated photoreceptor nuclei. At about $50 \mu \mathrm{m}$ from the ora terminalis, a second row of round, dark nuclei appears vitread to the first row. In this region, the original row of photoreceptor cells is maturing into cones. The inner nuclear layer adjacent to the ora terminalis is much thicker than in more central regions (Fig. 27), again resembling the situation in the developing larval retina.

These regional changes in nuclear densities in the outer and inner nuclear layers of the adult retina are illustrated by the cell counts in Table I. The data are representative counts from one retina of a small goldfish of $3.4 \mathrm{~cm}$ standard length. Further details are given in the legend to Table I. Cones and cells in the inner nuclear layer decreased in density with increased distance from the ora terminalis, whereas the density of rods increased. The ratio of rods to cones thus increased from 0 at the

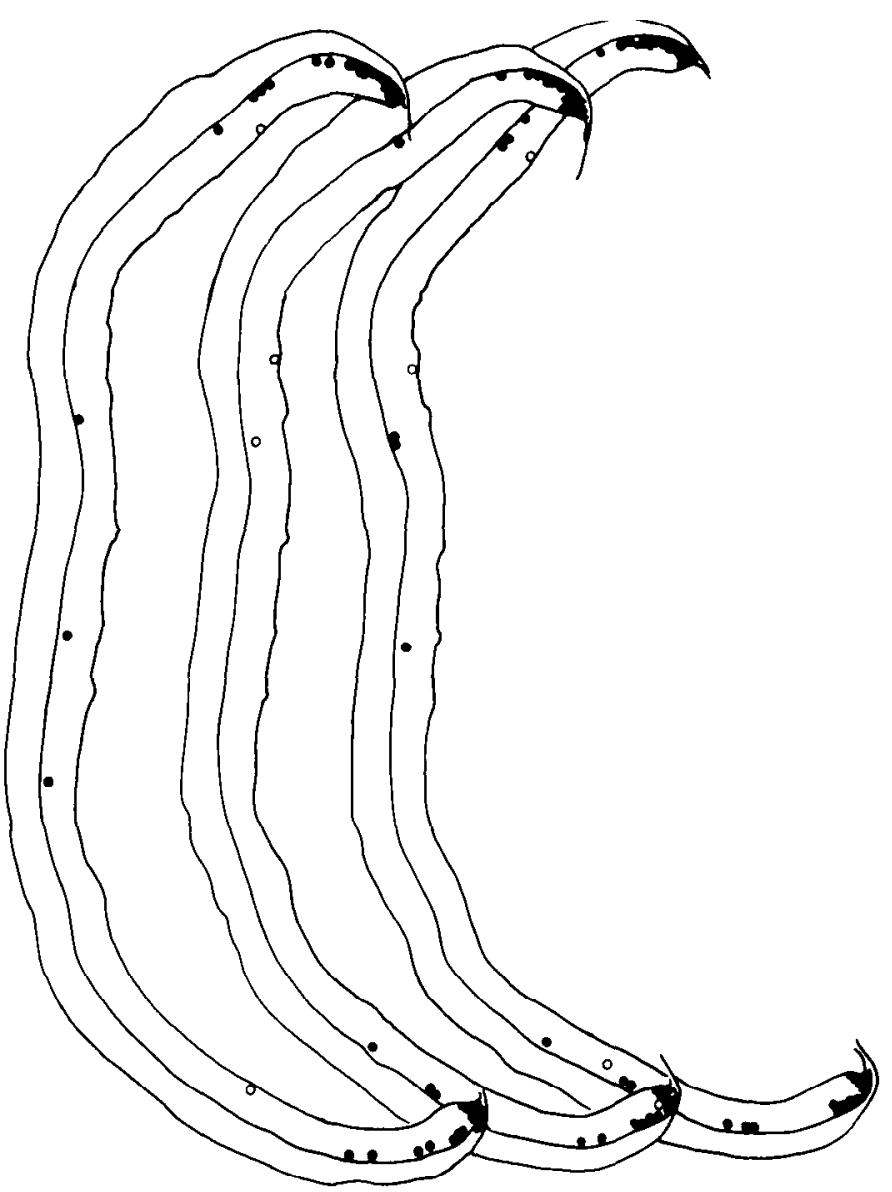

\section{$1.0 \mathrm{~mm}$}

Figure 24. Distribution of labeled nuclei across the retina of a juvenile goldfish. These are camera lucida drawings of three retinal sections from the same fish as in Figure 21. The internal limiting membrane, external limiting membrane, and pigmented retinal epithelium were traced. Each solid circle is a labeled nucleus in the outer nuclear layer or annular growth zone; each open circle is a labeled nucleus in the inner nuclear layer or vitread retinal layers. 


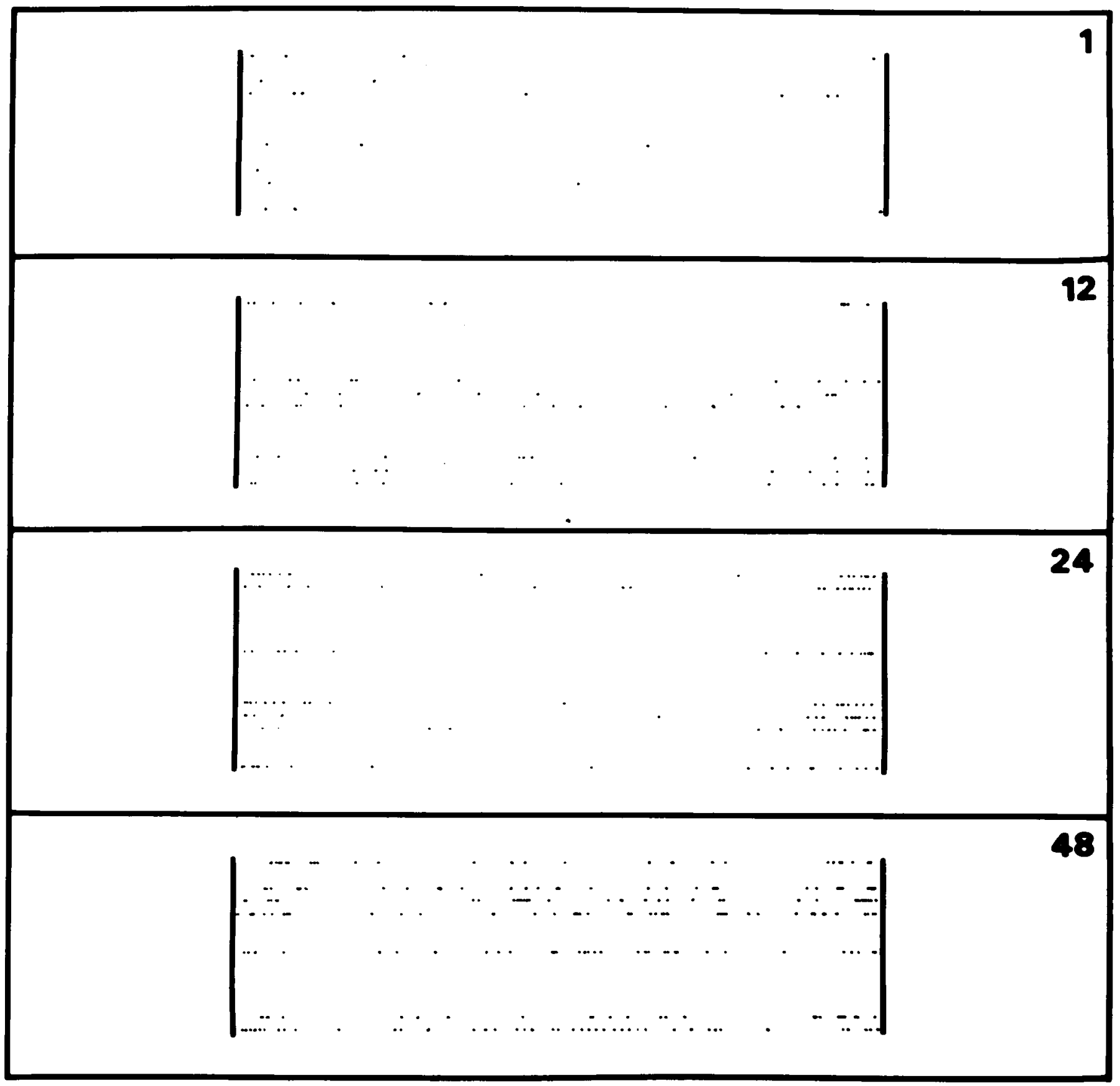

Figures 25 and 26. Distribution of labeled nuclei in the outer nuclear layer at various survival times. These are computermodified reconstructions of the positions of labeled nuclei in the outer nuclear layer generated from drawings such as those in Figure 24. Seven parameridional sections from each of 17 eyes were traced, and the positions of all labeled nuclei in the outer nuclear layer were noted. The eyes were from fish in both series of experiments (single and multiple injections). The tracings then were entered into the computer and the data were processed as follows. The curvilinear retinal sections were straightened and their overall length was adjusted to a fixed value; the relative positions of the labeled nuclei along the retinal arc were maintained. The transformed data were printed out as rows of dots, one row for each section and one dot for each labeled nucleus. The relative spacing between adjacent rows is proportional to the actual distance between the sections that were traced but greatly exaggerated for clarity. Each rectangular matrix of dots represents a narrow swatch of retina, on average, $50 \mu \mathrm{m}$ in height and bounded on each side by the ora terminalis, which is represented by vertical line segments. The numbers on the right are survival times in hours (Fig. 25) or days (Fig. 26). The dashed lines in the 180-day retina represent the labeled growth annulus.

margin to between 3.65 and 7.57 in the "periphery." The slightly higher ratio of rods to cones in the dorsal and nasal quadrants results from a slightly lower density of cones in those regions (Wheeler, 1978).

The results from histological observations and morphometric and radioautographic analyses are therefore in accord-in juvenile fish, rod nuclei accumulate at the peripheral edges of the retina, where abundant labeled rods and rod progenitors were found in the radioautographs. The conclusion which emerges is that the steps involved in the genesis of rods in larval retinas are recapitulated continuously at the growing perimeter of 


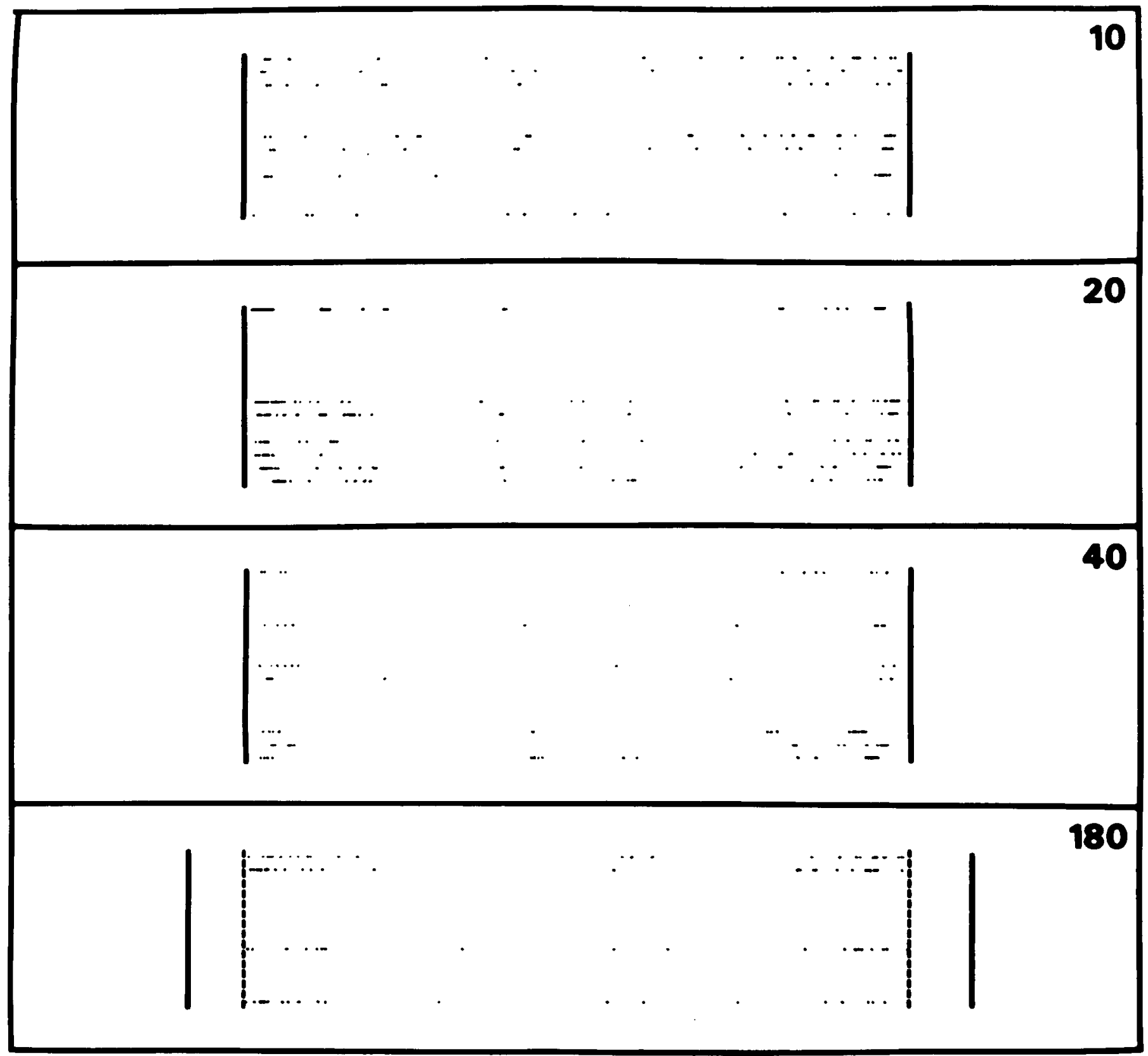

Figure 26.

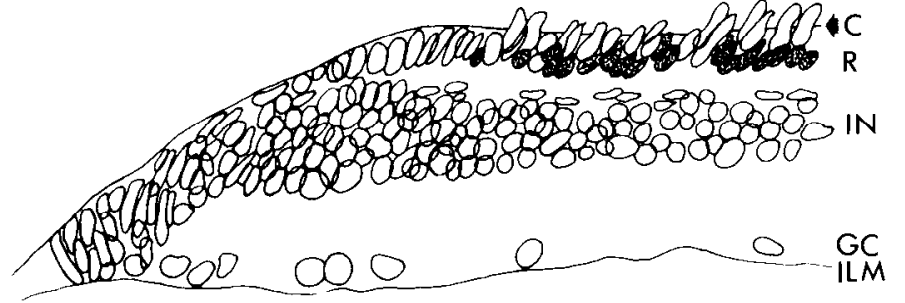

Figure 27. Camera lucida drawing of retinal cell nuclei in the far peripheral retina of a juvenile goldfish. The ora terminalis is at the left edge. Rod nuclei $(R)$ are stippled and cones $(C)$ and other nuclei are open. The external limiting membrane (arrow) and internal limiting membrane (ILM) are drawn. The inner nuclear layer $(I N)$ and ganglion cell layer $(G C)$ also are shown. The calibration bar is $50 \mu \mathrm{m}$. the juvenile and adult retina, where annuli of new retinal cells are generated by the circumferential germinal zone.

In the larval retina, the rod progenitors seem to be derived originally from clusters of undifferentiated cells in the inner nuclear layer, which later migrate across the outer plexiform layer to take up residence in the outer nuclear layer. The same ontogenetic history probably pertains to the rod progenitors in the immature regions of the growing juvenile and adult retina. Though undifferentiated cells were not recognized in retinas from older fish, there was an excess of cells in the inner nuclear layer near the ora terminalis, and labeled nuclei were observed apparently crossing the outer plexiform layer.

The ontogenesis of rods in the teleost retina: A proposal. I would therefore propose the following scheme. In the post-larval retina, the circumferential germinal zone is the ultimate source of all new retinal cells, whether differentiated retinal neurons or germinal cells 
TABLE I

Regional densities and ratios of rods and cones

The linear densities of nuclei of cones, rods, and cells in the inner nuclear layer (INL) and the ratios of the densities of rods to cones are given. Both eyes from one small fish were sectioned meridionally, the first eve in a plane parallel to the dorsoventral axis and the other parallel to the nasotemporal axis. Camera lucida drawings, such as those in Figure 24, were prepared of selected microscopic fields at a magnification of $\times 1,100$. Each field was $110 \mu \mathrm{m}$ in diameter. One field was adjacent to the ora terminalis and the other was located at a distance of about $870 \mu \mathrm{m}$ from the first. One meridional section was used from each eye, and drawings were prepared of both margins, representing each of the four retinal quadrants (nasal, temporal, dorsal and ventral). Nuclei of cone, rod, and inner nuclear layer cells were counted in three segments at increasing distance from the ora terminalis delineated as follows. The "margin" extended from the ora terminalis to the point at which developing cone nuclei first protruded through the external limiting membrane. The "juxtamargin" was the adjacent segment in the same microscopic field but was bounded centrally by the edge of the field. The "periphery" was a segment the full width of the second field. Linear densities are given in the first three columns and the ratio of rods to cones is given in the last column (the densities used to compute ratios were corrected for split nuclei).

\begin{tabular}{lrrrl} 
& Rods/mm & Cones/mm & INL/mm & Rods:Cones \\
\hline Nasal & & & & \\
Margin & 0 & 321 & 1161 & 0 \\
Juxtamargin & 185 & 259 & 815 & 0.71 \\
Periphery & 768 & 126 & 421 & 6.10 \\
& & & & \\
Temporal & & & & \\
Margin & 0 & 344 & 1344 & 0 \\
Juxtamargin & 256 & 231 & 923 & 1.11 \\
Periphery & 778 & 148 & 696 & 5.25 \\
& & & & \\
Dorsal & & & & \\
Margin & 47 & 302 & 1140 & 0.16 \\
Juxtamargin & 265 & 279 & 824 & 0.95 \\
Periphery & 1392 & 184 & 618 & 7.57 \\
& & & & \\
Ventral & & & & \\
Margin & 20 & 451 & 1255 & 0.04 \\
Juxtamargin & 261 & 328 & 845 & 0.80 \\
Periphery & 635 & 174 & 772 & 3.65 \\
\hline P & & & &
\end{tabular}

in the outer or inner nuclear layers. As the circumferential germinal zone spins off annuli of new cells, those destined to become ganglion cells, inner nuclear layer cells, and cones differentiate immediately, whereas other progeny remain undifferentiated. These are sequestered initially in the inner nuclear layer where they may persist in dividing, but eventually, they move into the outer nuclear layer as rod progenitors. Once there, they divide to produce rods.

A final word should be included about the fate of the labeled rod progenitors in the more central regions where the retina is fully differentiated and the outer nuclear layer contains a complete complement of rods. Why do these cells persist in generating rods? Recall that the differentiated retina grows by expanding, and all retinal cells except the rods are more spread apart in larger eyes. It seems likely that these additional rods which are inserted into the retina throughout its extent are required to maintain the density of rods constant in the face of retinal expansion. Thus, the developmental period over which rods are born is not only delayed until larval life but it is also greatly prolonged as rods continue to be added to the fully differentiated retina of the adult fish.

\section{Discussion}

The notion that, during postembryonic growth of the retina, cell proliferation is restricted to the ora terminalis, sometimes called ora serrata or ciliary margin, has dominated the literature and influenced the interpretation of results since the earliest studies (Schultze, 1866; Glücksmann, 1940; Müller, 1952). Walls (1967) called it a "perennial mystery" that the size of the retina in fish and amphibians increased greatly after cell division had ceased throughout most of its extent, and he surmised that cells must be added at the ciliary margin. It is not difficult to understand why this concept was originally formulated and why it was embraced so wholeheartedly thereafter. To begin with, histological examination of the retina of a fish, a frog, or a salamander reveals a discrete collection of undifferentiated cells at the ora terminalis. The appearance of these cells is unquestionably similar to neuroepithelial germinal cells (Stone, 1959; Müller, 1952; Fujita, 1963, 1964; Wagner, 1974; Johns, 1977), and mitotic figures have been observed next to the apical surface (the external limiting membrane) of the neural retina at the ora terminalis (Müller, 1952; Lyall, 1957a; Wagner, 1974). Moreover, the location of the dividing cells at the ora terminalis can be viewed simply as a failure to terminate the final stage of embryonic development (Johns, 1981). Also in support of circumferential growth is the fact that retinal regions adjacent to the perimeter are cytologically immature (Johns, 1981), and as pointed out in this study and in previous work (Müller, 1952; Lyall, 1957a, b; Wagner, 1974), the various stages of retinal maturation seen in developing larvae are laid out sequentially in the periphery of the retina of juvenile and adult fish. Thus, the dogma of the circumferential germinal zone arose. When $\left[{ }^{3} \mathrm{H}\right]$ thymidine radioautography became available as a technique for identifying proliferating cells and labeling their progeny, the initial results substantially confirmed these suppositions.

Despite its appeal, a number of observations have been difficult to reconcile with the concept that postembryonic cell addition is confined to the ora terminalis. First, there is abundant evidence that the proportion of rods increases during growth in teleost fish. It has been reported that, in several species of marine teleosts, the larval forms have cones but no rods, whereas the adult has both (Ali, 1959, 1961; Blaxter, 1968, 1975; Blaxter and Jones, 1967; Blaxter and Staines, 1970). The histological evidence for this conclusion was, in these initial papers, somewhat indirect. Rod outer segments in the teleost retina are narrow and not easily resolved in the paraffin sections that were used, and therefore, the determination of photoreceptor types relied on a comparison between the total number of cone processes (which are larger and more easily seen than those of rods) and the total number of nuclei in the outer nuclear layer (which would include rods, if present, and cones). This ratio was approximately 1:1 in larval retinas but greater after metamorphosis. In a study of retinal histogenesis in a cichlid, Nannacara anomala, Wagner (1974) found two types of differentiated cones in the retina when larvae began to swim freely (at about 5 days), but he could not recognize rods until the fish were 16 days old. A remarkable and most unusual case of postembryonic addition of rods in the teleost retina was described by Locket (1980). The deep 
sea fish, Chauliodus sloani, has a "pure rod" retina in which the visual processes of the rods are stacked in multiple tiers or banks. Small specimens $(3 \mathrm{~cm}$ standard length) had only one tier of rods, but larger fish had more, up to five tiers in the largest fish $(25 \mathrm{~cm}$ in length). The convergence ratio of total rods to total cells in the ganglion cell layer (he did not distinguish ganglion cells from glia) rose from 7:1 to 200:1. In guppies (Lebistes reticulatus), the ratio of rods to ganglion cells increases from 12:1 to 25:1 during postembryonic life (Müller, 1952). In the retina of the trout (Salmo trutta), Lyall $(1957 \mathrm{a}, \mathrm{b})$ found that there were two rows of rod nuclei in newly hatched fry, whereas in the retina of adults, there were three rows of rod nuclei.

Identifying the source of the additional rods has proven to be problematical, however. Müller (1952) thought that new rods were displaced laterally from the germinal zone at the ora terminalis. Lyall (1957a) speculated that cones were transformed into rods, since she observed that one kind of cone, the so-called additional single, gradually disappeared from the retina while the rods accumulated. The number of cones lost was not sufficient to account for the total number of rods acquired; therefore, in another paper (Lyall, 1957b), she proposed that the inner nuclear layer might be an additional source of cells with which to augment the population of rods. Blaxter and colleagues, in their original papers (summarized in Blaxter, 1975), also favored this second alternative. Interestingly, Bernard (1900) had earlier suggested a similar scheme (migration of cells from the inner nuclear layer to the outer nuclear layer and then transformation of cones into rods) to explain the increase in the proportion of rods in the retinas of adult frogs compared with those of tadpoles.

In a very recent report, Sandy and Blaxter (1980) have presented a new interpretation of the ontogenesis of rods in the larval teleost retina, and the present results largely confirm their findings. In their study, they, too, used plastic-embedded tissue for better histological resolution and combined it with thymidine radioautography to identify the new rods and their progenitors. They demonstrated that the rods were derived from a population of scattered germinal cclls, which they called "basal cells" because they were located along the vitread border of the outer nuclear layer. The rod progenitors described in the present study are certainly analogous to their basal cells, though, in goldfish, the dividing cells were not always located at the border of the outer plexiform layer. Sandy and Blaxter (1980) concluded that, in sole (Solea solea), one of the two species of fish that they used, some of the earliest photoreceptors generated by the basal cells differentiated into cones. In contrast, there was no evidence for the scattered addition of new cones to the central retina in goldfish, though it was clear from the pattern of labeling at the central edge of the labeled growth annulus in young larvae that cones and some horizontal cells are the last neurons to be formed by the traditional embryonic mode of ventricular cell proliferation. This is in accord with an earlier study by Sharma and Ungar (1980) which described the order of birth of neurons in the embryonic goldfish retina.

In earlier papers, there had been hints that the rods which accumulate in the larval teleost retina might be derived from proliferating cells within the retina instead of in the circumferential germinal zone. Baburina (1955, cited in Sandy and Blaxter, 1980) and Ahlbert (1976) both observed mitotic figures in the outer nuclear layer and suggested that these might be producing rods. Lyall (1957a) also mentioned finding an occasional mitotic figure in the outer nuclear layer, though she did not associate them with the genesis of rods. Scholes (1976) studied early postembryonic stages in the histogenesis of the retina in black mollies, a cyprinid related to goldfish. In some preparations of retinas from fish injected with $\left[{ }^{3} \mathrm{H}\right]$ thymidine, he observed labeled cells within the outer nuclear layer adjacent to the ora terminalis, and he suggested that this was the site of rod production. Because he did not always find labeled nuclei there, even when cells in the circumferential germinal zone were labeled, he speculated that division of the rod precursors was "episodic" in some unspecified way. In the present study, capricious labeling of rod progenitors was noted also, but because multiple injections did not result in more equivalent labeling, it is proposed that individual differences in the numbers of progenitors or in the kinetics of the cell cycle might account for the variability among animals.

None of the previous investigators commented on the origin of the rod progenitors. In the early larval goldfish retina, before the first rods appear at 3 days, the outer nuclear layer is a single row of postmitotic nuclei (Marotte, 1980; present results), and rod progenitors are seemingly absent. An inspection of published micrographs reveals that the same is true of the retinas of the two fish used by Sandy and Blaxter (1980, Figs. $1 B$ and $2, A$ and $B$ ) as well as those of a cichlid, Tilapia leucosticta, studied by Grün (1975, Fig. $4 A$ ). Since the original cells in the outer nuclear layer appear to differentiate into cones, the rod progenitors must come from elsewhere. ${ }^{3}$ Another possible source is the proliferating population of cells in the inner nuclear layer. Sandy and Blaxter (1980) did not mention finding labeled nuclei in the inner nuclear layer, though one can be seen in their Figure $3 F$. It is difficult to identify these cells with certainty in part because of the variety of cells found in the inner nuclear layer, including both neurons and the Muller glial cell. Though it has not been shown that Muller cells in the postembryonic retina can divide, glial cells elsewhere in the central nervous system do so (reviewed by Korr, 1980; Skoff, 1980). I have suggested that the labeled cells in the inner nuclear layer are not glia but undifferentiated clusters of neuroepithelial germinal cells and that these are the precursors of rod progenitors. Until radioautographical studies are done at the electron microscopic level, however, this idea will remain speculative.

I would suggest that rod progenitors in the retina of larval and adult goldfish are formally analogous to subventricular cells of the embryonic neural epithelium (Boulder Committee, 1970). Subventricular cells are secondary germinal cells derived from the original neuroepithelial (ventricular) cells of the neural tube. During

\footnotetext{
Another possibility is that the rod progenitors undergo a mitotically quiescent phase around the time of hatching. If so, they might temporarily cease incorporation of $\left[{ }^{3} \mathrm{H}\right]$ thymidine and therefore would be hard to distinguish from the young postmitotic cones.
} 
the last phases of neurogenesis, these cells migrate away from the ventricle but continue to proliferate and give rise to late formed, small neurons and eventually glia. One of the best studied populations of subventricular cells is the external granular layer in the developing mammalian cerebellum (cf., Altman, 1972). This transient layer of proliferating cells is responsible for producing the granule cells of the cerebellar cortex, most of which are formed postnatally. My reasons for suggesting that the rod progenitors are subventricular cells are that (i) the fate of their progeny is limited to one type of neuron, (ii) they proliferate during the later stages of retinal histogenesis, and (iii) they divide in situ.

The delayed and prolonged period of rod genesis in the teleost retina is not entirely surprising, since, in most developing retinas, the photoreceptors are the last neurons to be born (Sidman, 1960; Hollyfield, 1972; Kahn, 1974) and the photoreceptor layer is often the last to mature (Ramón y Cajal, 1909-1911; Mann, 1969; Nilsson and Crescitelli, 1969; Vogel, 1978). In an elegant radioautographical study, Carter-Dawson and LaVail (1979) demonstrated that, in the mouse retina, the developmental period over which rods are born is both later and more prolonged than that of cones. Other work shows that, in the mammalian retina, the differentiation of rods lags behind that of cones. Smelser and colleagues (1974) demonstrated that, in the developing primate retina (Macaca mulatta), the synaptic contacts of cones were formed before those of rods. Likewise, in larval goldfish, rod spherules are rare at early stages of development (Graf et al., 1979). In contrast, Nilsson (1964) and Chen and Witkovsky (1978) have reported that rods and cones differentiate simultaneously in the retina of amphibians. The present results suggest that the development of photoreceptors in fish more closely resembles the mammalian than the amphibian pattern.

The present results demonstrate that new rods are inserted into the sheet of photoreceptors throughout the growing retina in larval goldfish and at a reduced rate in older fish. In a previous radioautographic study of retinal growth in juvenile and adult goldfish, the dividing rod progenitors were not recognized (Johns, 1977). The reason that they were overlooked is that few, if any, of them were labeled. There are several reasons which might account for this lack of labeling. The present experiments were done on fish which had been acclimated to the laboratory and were well fed and growing rapidly, and I suspect that the fish used in the previous experiments were not as healthy. Cell counts indicate that the number of retinal neurons is related directly to the size of the fish and is somewhat independent of age (Müller, 1952; Johns and Easter, 1977). This suggests that fish which grow slowly do not add as many neurons. ${ }^{4}$ I have some preliminary evidence that the mitotic rate of retinal germinal cells may be linked to the state of health or rate of growth of the fish (P. R. Johns, unpublished observations). Second, though the total dose of radioactivity administered in both experiments was approximately equivalent, the

\footnotetext{
${ }^{4}$ It should be noted that changes in the amount of cell death also could contribute to changes in the net rate of cell addition; there is, however, no evidence at present that cells die in these postembryonic retinas.
}

specific activity was much higher in the present study (100 versus $60 \mathrm{Ci} / \mathrm{mmol}$ ). With the higher specific activity, the level of labeling in each nucleus and the number of labeled nuclei were both higher. Thymidine is toxic to dividing cells (Pelc, 1963; Cleaver, 1967; Pollack et al., 1979) and the higher concentrations that were given with the isotope of lower specific activity in the previous study may have been sufficient to damage the germinal cells. The final problem is both technical and conceptual. A few labeled dividing nuclei were seen scattered across the retina in the earlier preparations, but they were so rare that they were dismissed as glial or vascular elements and therefore unimportant, in accord with previous interpretations (Straznicky and Gaze, 1971). It also reflects, in a more general sense, the difficulties of analyzing cell proliferation in differentiated tissue. The size and density of the precursor population is low, and many sections must be scanned in search of labeled nuclei. In addition, there is the problem, to which I alluded earlier, of identifying proliferating cells in the mature retina, since some of the labeled nuclei clearly belong to glial cells and vascular elements. In the retinas of fish, wandering phagocytes, either escaped from blood vessels or detached from the pigmented retinal epithelium, have been described (O'Day and Young, 1978; Braekevelt, 1980; P. R. Johns, unpublished observations). Most of these cells are in the extraretinal space between the neural retina and pigmented retinal epithelium, but they can be found anywhere within the retina. Mitotic activity in all of these non-neuronal cells is stimulated under certain conditions of disease or trauma (Korr, 1980; Skoff, 1980; Machemer and Laqua, 1975). The presence of such cells obscures the search for labeled ncurons or neuronal progenitors, since identification of these cells in the retina is often difficult, if not impossible, with traditional paraffin histology. Resolution is poor, and it is made worse by the overlying radioautographic emulsion. Moreover, the nuclei of the labeled cells are covered by silver grains, which further obscures cytological details. These problems have been partially overcome with methacrylate histology; the next step is to take the radioautographic analysis to the electron microscopic level.

There are many more unanswered questions. Why does the genesis of rods in the teleost retina follow such a unique course? Why are rods the only cells whose birth is delayed until larval life? How are the new rods inserted into the existing neuronal circuitry and what modifications are made to accommodate them? What are the visual consequences of the continually increasing fraction of rods in the growing teleost retina? Why do rods persist in accumulating in the adult retina, and why is their density maintained constant as the retina expands? In searching for an answer to the last question, we inevitably return to what is most special about the teleost retinait continues to grow and the overall increase in size is enormous. If the rods were to spread apart with growth, the visual sensitivity of the eye might suffer. The function of rods is to capture quanta of light under conditions of low levels of illumination, and their probability of success depends, in part, on a tight packing density. Preliminary psychophysical evidence suggests that, in fact, the absolute visual threshold is equivalent in large and small goldfish (M. K. Powers, personal communication). 
The radioautographic analysis presented here included fish ranging from newly hatched larvae to juveniles up to about 1 year of age. Retinal growth by the addition of cells at the circumferential germinal zone continues in older adult goldfish as previous morphometric and radioautographic studies have shown (Johns and Easter, 1977; Johns, 1977), though there is some indication that cell addition may slow down or even cease eventually in old fish (Kock and Reuter, 1978; Johns, 1981). Though thymidine radioautography has not yet been done on large goldfish, in sexually mature adult cichlids, the pattern of labeling following $\left[{ }^{3} \mathrm{H}\right]$ thymidine injections is essentially the same as described here for juvenile goldfish: dividing cells were found in the circumferential germinal zone and scattered across the retina in the outer nuclear layer (Johns and Fernald, 1981).

\section{References}

Abercrombie, M. (1946) Estimation of nuclear population from microtome sections. Anat. Rec. 94: 239-247.

Abercrombie, M. (1977) Concepts in morphogenesis. Proc. R. Soc. Lond. (Biol.) 99: 337-344.

Ahlbert, I. B. (1976) Organization of the cone cells in the retinae of salmon (Salmo salar) and trout (Salmo trutta trutta) in relation to their feeding habits. Acta Zool. (Stockh.) 57: 1335.

Ali, M. A. (1959) The ocular structure, retinomotor and photobehavioral responses of juvenile Pacific salmon. Can. J. Zool. 37: 965-995.

Ali, M. A. (1961) Histophysiological studies on the juvenile Atlantic salmon (Salmo salar) retina. I. Responses to light intensities, wavelengths, temperatures and continuous light and dark. Can. J. Zool. 39: 511-526.

Ali, M. A. (1963) Correlation of some retinal and morphological measurements from the Atlantic salmon (Salmo salar). Growth 27: 57-76.

Ali, M. A. (1964) Stretching of the retina during growth of salmon (Salmo salar). Growth 28: 83-89.

Allee, W. C., A. J. Kinel, and W. H. Hoskins (1940) The growth of goldfish in homotypically conditioned water: A population study in mass physiology. J. Exp. Zool. 84: 417-443.

Altman, J. (1972) Postnatal development of the cerebellar cortex in the rat. I. The external germinal layer and the transitional molecular layer. J. Comp. Neurol. 145: 353-398.

Beach, D. A., and M. Jacobson (1979) Patterns of cell proliferation in the retina of the clawed frog during development. $J$. Comp. Neurol. 183: 603-614.

Bernard, H. M. (1900) Studies in the retina: Rods and cones in the frog and in some other amphibia. Q. J. Microsc. Sci. 43: 23-47.

Blaxter, J. H. S. (1968) Light intensity, vision and feeding in young plaice. J. Exp. Mar. Biol. Ecol. 2: 293-307.

Blaxter, J. H. S. (1975) The eyes of larval fish. In Vision in Fishes: New Approaches in Research, M. A. Ali, ed., pp. 427-444, Plenum Press, New York.

Blaxter, J. H. S., and M. P. Jones (1967) The development of the retina and retinomotor response in the herring. J. Mar. Biol. Assoc. U. K. 47: 677-697.

Blaxter, J. H. S., and M. Staines (1970) Pure cone retinae and retinomotor responses in larval teleosts. J. Mar. Biol. Assoc. U. K. 50: 449-460.

Boulder Committee (1970) Embryonic vertebrate central nervous system: Revised terminology. Anat. Rec. 166: 257-262.

Braekevelt, C. R. (1980) Wandering phagocytes at the retinal epithelium-photoreceptor interface in the teleost retina. Vision Res. 20: 495-499.
Carter-Dawson, L. D., and M. M. LaVail (1979) Rods and cones in the mouse retina. II. Autoradiographic analysis of cell generation using tritiated thymidine. J. Comp. Neurol. 188: 263-272.

Cavineas, V. S., and D. S. Barkley (1971) Section thickness and grain count variation in tritium autoradiography. Stain Technol. 46: 131-135.

Chen, F., and P. Witkovsky (1978) The formation of photoreceptor synapses in the retina of larval Xenopus laevis. J. Neurocytol. 7: 721-740.

Cleaver, J. E. (1967) Thymidine Metabolism and Cell Kinetics, North Holland Publishing Co., Amsterdam.

Easter, S. S., P. R. Johns, and L. Baumann (1977) Growth of the adult goldfish eye. I. Optics. Vision Res. 17: 467-477.

Fujita, S. (1963) The matrix cell and cytogenesis in the developing central nervous system. J. Comp. Neurol. 120: 37-42.

Fujita, S. (1964) Analysis of neuron differentiation in the central nervous system by tritiated thymidine autoradiography. J. Comp. Neurol. 122: 311-327.

Gaze, R. M., and W. E. Watson (1968) Cell division and migration in the brain after optic nerve lesions. In Symposium on Growth of the Nervous System, London, 1967, G. E. W. Wolsten-Holme and M. O'Connor, eds., pp. 53-67, Churchill Ltd., London.

Glücksman, A. (1940) Development and differentiation of the tadpole eye. Br. J. Ophthalmol. 24: 153-178.

Graf, S. A., W. K. Stell, and S. C. Sharma (1979) Synaptogenesis of rods in goldfish. Invest. Ophthalmol. Vis. Sci. Suppl. 18: 82.

Grün, G. (1975) Structural basis of the functional development of the retina in the cichlid Tilapia leucosticta (teleostei). J. Embryol. Exp. Morphol. 33: 243-257.

Hollyfield, J. G. (1972) Histogenesis of the retina in the killifish Fundulus heteroclitus. J. Comp. Neurol. 144: 373-380.

Jacobson, M. (1976) Histogenesis of retina in the clawed frog with implication for the pattern of development of retinotectal connections. Brain Res. 103: 541-545.

Johns, P. R. (1977) Growth of the adult goldfish eye. III. Source of the new retinal cells. J. Comp. Neurol. 176: 343-358.

Johns, P. R. (1980) Goldfish retina has two kinds of germinal cells: One is specific for rods. Soc. Neurosci. Abstr. 6: 639 .

.Johns, P. R. (1981) Growth of fish retinas. Am. Zool. 21: 441453.

Johns, P. R., and S. S. Easter (1977) Growth of the adult goldfish eye. II. Increase in retinal cell number. J. Comp. Neurol. 176: 331-342.

Johns, P. R., and R. D. Fernald (1981) Genesis of rods in the retina of teleost fish. Nature 293: 141-142.

Johns, P. R., and Y. Hwang (1981) Retinal development in larval goldfish: Delayed formation of rods. Invest. Ophthalmol. Vis. Sci. Suppl. 20: 150.

Kahn, A. J. (1974) An autoradiographic analysis of the time of appearance of neurons in the developing chick neural retina. Dev. Biol. 38: 30-40.

Kajishima, T. (1960) The normal developmental stages of the goldfish, Carassius auratus. Jpn. J. Ichthyol. 8: 20-28.

Kock, J. -H., and T. Reuter (1978) Retinal ganglion cells in the crucian carp (Carassius carassius). I. Size and number of somata in eyes of different size. J. Comp. Neurol. 179: 535548 .

Konigsmark, B. W. (1970) Methods for the counting of neurons. In Contemporary Research Methods in Neuroanatomy, W. J. H. Nauta and S. O. E. Ebbesson, eds., pp. 315-340, Springer-Verlag, New York.

Korr, H. (1980) Proliferation of differential cell types in the brain. Adv. Anat. Embryol. Cell Biol. 16: 1-72.

Locket, N. A. (1980) Variation of architecture with size in the multiple-bank retina of a deep-sea teleost, Chauliodus sloani. Proc. R. Soc. Lond. (Biol.) 208: 223-242. 
Lyall, A. H. (1957a) The growth of the trout retina. Q. J. Microsc. Sci. 98: 101-110.

Lyall, A. H. (1957b) Cone arrangement in teleost retinae. Q. J. Microsc. Sci. 98: 189-201.

Machemer, R., and H. Laqua (1975) Pigment epitheliunı proliferation in retinal detachment (massive periretinal proliferation). Am. J. Ophthalmol. 80: 1-23.

Mann, I. (1969) The Development of the Human Eye, Grune and Stratton, New York.

Marotte, L. R. (1980) Goldfish retinotectal system: Continuing development and synaptogenesis. J. Comp. Neurol. 193: 319334.

Meyer, R. L. (1978) Evidence from thymidine labeling for continuing growth of retina and tectum in juvenile goldfish. Exp. Neurol. 59: 99-111.

Mori, H., and K. Christensen (1980) Morphometric analysis of Leydig cells in the normal rat testis. J. Cell Biol. 84: 340-354.

Müller, H. (1952) Bau und Wachstum der Netzhaut des Guppy (Lebistes reticulatus). Zool. Jahrb. Abt. Allg. Zool. Physiol. Tiere 63: 275-324.

Nilsson, S. E. G. (1964) Receptor cell outer segment development and ultrastructure of the disc membranes in the retina of the tadpole (Rana pipiens). J. Ultrastruct. Res. 11: 581620.

Nilsson, S. E. G., and F. Crescitelli (1969) Changes in ultrastructure and electroretinogram of bullfrog retina during development. J. Ultrastruct. Res. 27: 45-62.

O'Day, W. T., and R. W. Young (1978) Rhythmic daily shedding of outer segment membranes by visual cells in goldfish. J. Cell Biol. 76: 593-604.

Pelc, S. R. (1963) On the question of renewal of differentiated cells. Exp. Cell Res. 29: 194-198.

Pollack, A., C. B. Bagwell, and G. L. Irvin (1979) Radiation from tritiated thymidine perturbs the cell cycle progression of stimulated lymphocytes. Science 203: 1025-1027.

Ramón y Cajal, S. (1909-1911) Histologie du Systeme Nerveaux del'Homme et des Vertèbres, L. Azoulay, translator, reprinted (1952-1955) by Institute Ramón y Cajal del Consejo Superior de Investigaciones Cientificas, Madrid.
Rugh, R. (1962) Experimental Embryology: Techniques and Procedures, Ed. 3, Burgess Publishing Co., Minneapolis.

Sandy, J. M., and J. H. S. Blaxter (1980) A study of retinal development in larval herring and sole. J. Mar. Biol. Assoc. U. K. 60: 59-71.

Scholes, J. H. (1976) Neuronal connections and cellular arrangement in the fish retina. In Neural Principles in Vision, F. Zettler and R. Weiler, eds., pp. 63-93, Springer-Verlag, New York.

Schultze, M. (1866) Anatomie und Physiologie der Netzhaut. Arch. Microsk. Anat. Entw. Mech. 2: 175-286.

Sharma, S. C., and F. Ungar (1980) Histogenesis of the goldfish retina. J. Comp. Neurol. 191: 373-382.

Sidman, R. L. (1960) Histogenesis of mouse retina studied with thymidine- $\mathrm{H}^{3}$. In The Structure of the Eye, G. K. Smelser, ed., pp. 487-506, Academic Press, New York.

Skoff, R. P. (1980) Neuroglia: A reevaluation of their origin and development. Pathol. Res. Pract. 168: 279-300.

Smelser, G. K., V. Ozanics, M. Rayborn, and D. Sagun (1974) Retinal synaptogenesis in the primate Macaca mulatta. Invest. Ophthalmol. Vis. Sci. 13: 340-361.

Stell, W. K., and F. I. Hárosi (1976) Cone structure and visual pigment content in the retina of the goldfish. Vision Res. 16: 647-657.

Stone, L. S. (1959) Experiments testing the capacity of iris to regenerate neural retina in eyes of adult newts. J. Exp. Zool. 142: $285-308$.

Straznicky, K., and R. M. Gaze (1971) The growth of the retina in Xenopus laevis: An autoradiographic study. J. Embryol. Exp. Morphol. 26: 67-79.

Wagner, H. J. (1974) Development of the retina of Nannacara anomala, with special reference to regional variations of differentiation. Z. Morphol. Tiere 79: 113-131.

Walls, G. L. (1967) The Vertebrate Eye and Its Adaptive Radiation, Hafner Publishing Co., New York.

Wheeler, T. G. (1978) Goldfish retina-dorsal versus ventral areas. Vision Res. 18: 1329-1336.

Vogel, M. (1978) Postnatal development of the cat's retina. Adv. Anat. Embryol. Cell Biol. 54: 4-65. 